Portland State University

PDXScholar

$5-3-1990$

\title{
Differentially Diagnosing Stuttering in Young Children Using the Stuttering Severity Instrument
}

\author{
Brenda Pekkola Teich \\ Portland State University
}

Follow this and additional works at: https://pdxscholar.library.pdx.edu/open_access_etds

Part of the Speech Pathology and Audiology Commons Let us know how access to this document benefits you.

\section{Recommended Citation}

Teich, Brenda Pekkola, "Differentially Diagnosing Stuttering in Young Children Using the Stuttering Severity Instrument" (1990). Dissertations and Theses. Paper 4135.

https://doi.org/10.15760/etd.6018

This Thesis is brought to you for free and open access. It has been accepted for inclusion in Dissertations and Theses by an authorized administrator of PDXScholar. Please contact us if we can make this document more accessible: pdxscholar@pdx.edu. 
AN ABSTRACT OF THE THESIS OF Brenda Pekkola Teich for the Master of Science in Speech Communication presented May 3, 1990.

Title: Differentially Diagnosing Stuttering In Young Children

Using the Stuttering Severity Instrument

APPROVED BY MEMBERS OF THE THESIS COMMITTEE:

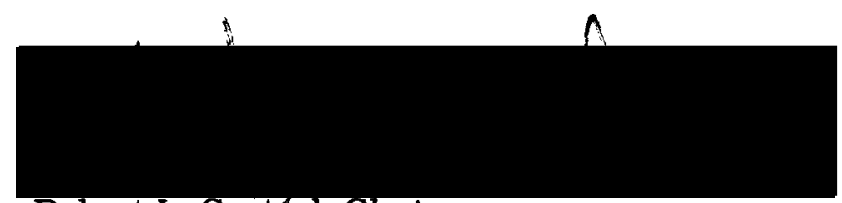

Robert L. Casteel, Chair

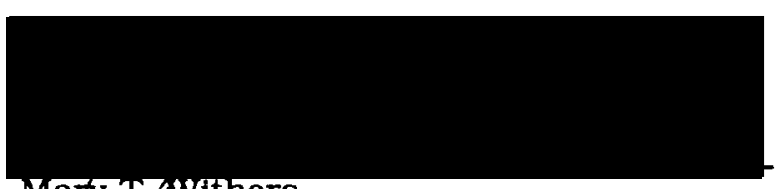

Mary T.owithers

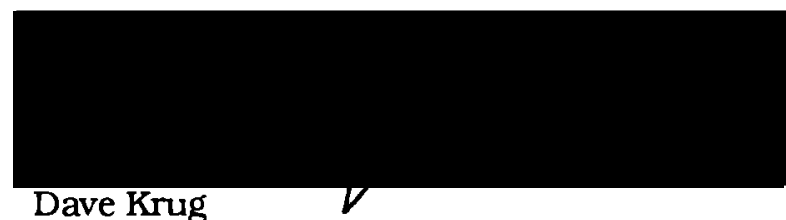

Young children between the ages of two and six years often exhibit partword, whole word, and phrases repetitions as their language develops. This is also the age range when stutterering most frequently appears. Consequently, speech-language pathologists need diagnostic criteria and evaluation tools to distinguish between the incipient stutterer and the normally disfluent child.

Today a widely used evaluation tool is the Stuttering Severity Instrument (SSI) (Riley, 1972, 1980). The SSI is designed to provide a severity level based upon the parameters of frequency, duration, and physical 
concomitants. Riley (1972) first designed the SSI to not include monosyllabic word repetitions in the frequency count; however, he revised the SSI in 1980 to Include monosyllablc word repetitions without providing new normative data nor standardization. It was questionable as to whether the SSI was a sufficiently sensitive means to determine stuttering severity for young children and to whether or not it was strengthened or weakened by the addition of whole monosyllabic words.

The primary question addressed was: Does the SSI discriminate between incipient stutterers and nonstutterers between the ages of two and six? The following secondary questions were also addressed:

1. Do disfluency types not addressed in the SSI contribute information which would provide a stronger discrimination between incipient stutterers and normally disfluent children?

2. Does either the incipient stutterers or nonstutterers exhibit a significant difference between the SSI scores of the speech samples elicited from picture sequence cards and open-ended questions?

3. Does the 1972 or 1980 SSI provide a better means of differentially diagnosing the incipient stutterer from the normally disfluent child?

Two groups of subjects were used in this study: one containing ten children, between the ages of two and six identified as stutterers by their primary caretaker and the second containing ten nonstutterers matched for age and sex of the stuttering subjects. All children were selected from the Portland metropolitan area and met the selection criteria. Spontaneous speech sample 
were obtained and recorded for each subject. The investigator then administered the SSI and categorized nine disfluency types.

The Mann-Whitney $U$ was used to analyze the data for the primary question. A statistically significant difference between the groups of inciplent stutterers and nonstutterers SSI scores was found at the .002 level of confidence. The SSI did not discriminate at an individual subject level. Often the SSI scores between the incipient stutterers and nonstutterers overlapped. In addition, the normally disfluent children were labeled as stutterers varying from very mild, to mild or moderate severities.

The results for the secondary questions yielded the following conclusions:

1. Four of the six disfluency types observed, polysyllabic word repetition, tense pauses, intrusive schwas and revision/incomplete phrases were found to be statistically significant at the .05 level of confidence.

2. Neither population exhibited a significant dufference between the elicitation procedures used to gather a speech sample. Although not significant, a slight tncrease in the total disfluency count was present in the picture elicitation among both groups.

3. Neither the 1972 nor 1980 versions of the SSI provided a statistically significant difference which would indicate that either version would be a better means of discriminating between the Incipient stutterers and normally disfluent children.

The results of this study indicate that the SSI labels normally disfluent children as stutterers as well as resulting in overlapping scores between the two 
sample populations. These inherent problems suggest that the speech-language pathologist should look at additional diagnostic indicators in assessing the disfluencies of children. 
DIFFERENTLALLY DLAGNOSING STUTTERING IN YOUNG CHILDREN USING THE STUTTERING SEVERITY INSTRUMENT

\author{
by \\ BRENDA PEKKOLA TEICH
}

A thesis submitted in partial fulfilment of the requirements for the degree of

\author{
MASTERS OF SCIENCE \\ in \\ SPEECH COMMUNICATION: \\ SPEECH AND HEARING SCIENCES
}

Portland State University

1990 
TO THE OFFICE OF GRADUATE STUDIES:

The members of the Committee approve the thesis of Brenda Pekkola Teich presented May 3, 1990.

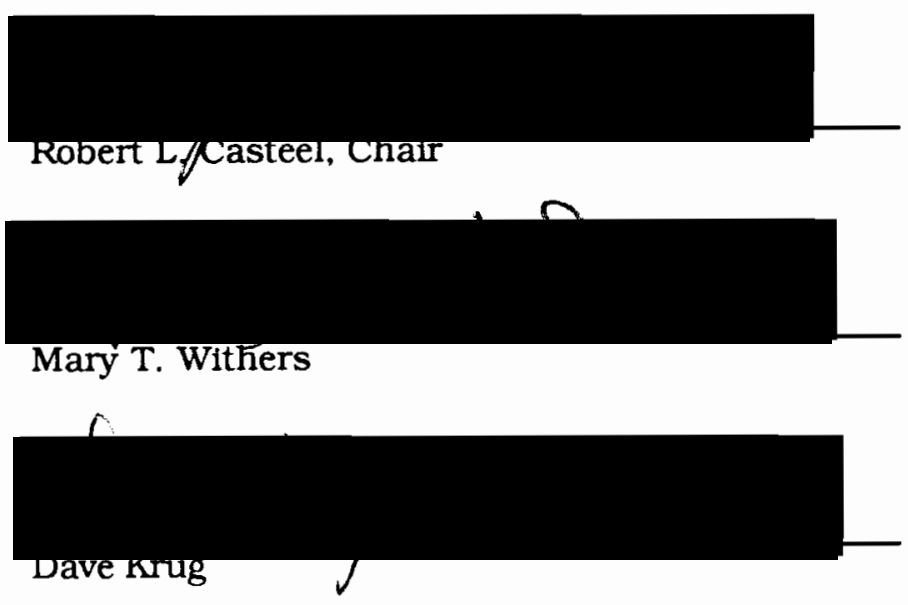

APPROVED:

Theodore G. Grove, Chair, Department of Speech Communication

C. William Savery, Interim Vice Provost fortraduate Studies and Research 


\section{ACKNOWLEDGEMENTS}

I wish to thank Dr. Robert Casteel for his advising and unending support and guldance throughout this project.

I am grateful to Mary T. Withers whose interests and comments were very helpful. I am fortunate to have had her participate on my committee.

A special thanks to Jack Hegrenes for generously giving of his time to help with the statistical preparation of this study. His patience and advice were invaluable in completing this project.

My deepest gratitude to my parents for their understanding and love. Their constant support throughout my undergraduate and graduate studies was greatly appreciated. Finally, I want to express my appreciation to my husband, Marty, whose patience, encouragement and love enabled me to complete this project. 


\section{TABLE OF CONTENTS}

PAGE

ACKNOWLEDGEMENTS $\ldots \ldots \ldots \ldots \ldots \ldots \ldots \ldots \ldots \ldots \ldots \ldots \ldots \ldots \ldots$

UST OF TABLES $\ldots \ldots \ldots \ldots \ldots \ldots \ldots \ldots \ldots \ldots \ldots \ldots \ldots \ldots$

\section{CHAPTER}

I INTRODUCTION AND STATEMENT OF PURPOSE $\ldots \ldots \ldots \ldots$ I

Introduction $\ldots \ldots \ldots \ldots \ldots \ldots \ldots \ldots \ldots \ldots \ldots \ldots \ldots, 1$

Statement of Purpose $\ldots \ldots \ldots \ldots \ldots \ldots \ldots \ldots \ldots \ldots \ldots, 2$

Definition of Terms ............................. 3

II REVIEW OF LTERATURE $\ldots \ldots \ldots \ldots \ldots \ldots \ldots \ldots \ldots \ldots \ldots \ldots$

Characteristics of Normally Disfluent

Children ................................ 5

Characteristics of Incipient Stutterers $\ldots \ldots \ldots \ldots \ldots \ldots \ldots$

Influence of Elicitation Procedures

On Stuttering Evaluations $\ldots \ldots \ldots \ldots \ldots \ldots \ldots \ldots, 11$

Historical Perspective of Evaluation

Methods .................................. 13

Comparisons of the 1972 and 1980

Stuttering Severity Instruments. . . . . . . . . . . . 15

III METHODS $\ldots \ldots \ldots \ldots \ldots \ldots \ldots \ldots \ldots \ldots \ldots \ldots \ldots \ldots \ldots, 19$

Subject Eligibility Procedures. . . . . . . . . . . . . . 20

Speech Sample Procedures. ..................... 20

Reliability............................... 22 
IV RESULTS AND DISCUSSION

PAGE

Results .................................. 25

Discussion..................................... 35

V SUMMARY AND IMPLICATIONS $\ldots \ldots \ldots \ldots \ldots \ldots \ldots \ldots$

Surnmary $\ldots \ldots \ldots \ldots \ldots \ldots \ldots \ldots \ldots \ldots \ldots \ldots \ldots, 39$

Clinical Implications $\ldots \ldots \ldots \ldots \ldots \ldots \ldots \ldots \ldots \ldots \ldots, 41$

Research Implications $\ldots \ldots \ldots \ldots \ldots \ldots \ldots \ldots \ldots \ldots, 43$

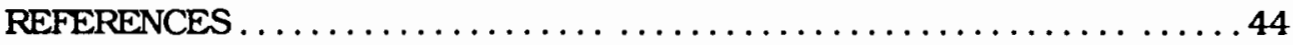

APPENDICES

A LETTER TO PARENTS AND PERMISSION TO

PARTICIPATE IN STUDY FORM . . . . . . . . . . . . 46

B PARENT PERMISSION FORM $\ldots \ldots \ldots \ldots \ldots \ldots \ldots \ldots \ldots \ldots$

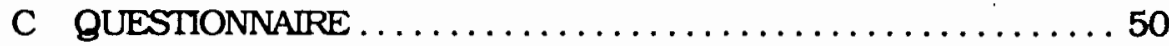

D LUST OF STIMULI ........................... 53

E CODING SYMBOLS $\ldots \ldots \ldots \ldots \ldots \ldots \ldots \ldots \ldots \ldots \ldots \ldots$

F THE SSI'S MANUAL ADMINISTRATION

INSTRUCTIONS. .........................57

G SSI SCORING PROCEDURES FOR RELIABILITY JUDGES .............................60

H STUTTERING SEVERITY INSTRUMENT TEST FORM . . . . . .63

I INSTRUCTIONS TO RELIABILITY JUDGES . . . . . . . . . .65

J INSTRUCTIONS FOR SELECTION OF CONTENT TRANSCRIPTS FOR RELIABILITY TESTING . . . . . . . . 69 
LIST OF TABLES

I A COMPARISON OF SEVERAL RESEARCHERS

FINDINGS ON NORMAL DISFLUENCIES.. . . . . . . 9

II 1972 SSI SEVERITY CONVERSION TABLE

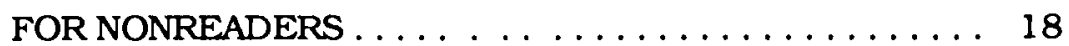

III 1980 SSI SEVERITY CONVERSION TABLE FOR NONREADERS $\ldots \ldots \ldots \ldots \ldots \ldots \ldots \ldots \ldots$

IV TEST SCORES AND SEVERITY RATINGS FOR SIX SUBJECTS FOR EACH OF THE THREE JUDGES. . . . . . 22

V PERCENTAGE OF INTERRATER AGREEMENTS OF SSI SCORES FOR EACH OF THE THREE JUDGES. . . . . . . 23

VI INTRAJUDGE RELIABILITY OF SSI TEST SCORES

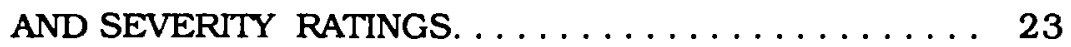

VII A COMPARISON OF 1980 SSI SCORES FOR STUTTERERS AND NONSTUTTERERS BETWEEN

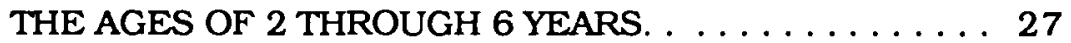

VIII RESULTS OF A ONE-TAILED T-TEST FOR UNRELATED MEANS COMPARING THE DISFLUENCY TYPES NOT ADDRESSED IN THE SSI BETWEEN INCIPIENT STUTTERERS AND NONSTUTTERERS. . . . . . . . 29

IX A COMPARISON OF THE MEANS AND STANDARD DEVIATIONS AND RANKINGS FOR SPECIFIC TYPES OF DISFLUENCIES FOR STUTTERERS AND

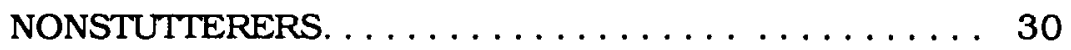

X A COMPARISON OF THE SSI SCORES FOR PICTURE

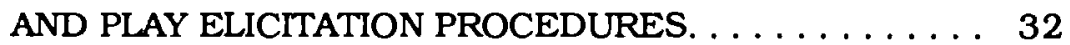

XI A COMPARISON OF THE MEANS AND STANDARD DEVIATIONS OF DISFLUENCIES FOR STUTTERERS AND NONSTUTTERERS IN A PLAY ELICITATION PROCEDURE 
PAGE

XII A COMPARISON OF THE MEANS AND STANDARD DEVIATIONS OF DISFLUENCIES FOR STUTTERERS AND NONSTUTTERERS IN A PICTURE

ELICITATION PROCEDURE.. . . . . . . . . . . . . . 34

XIII A COMPARISON OF THE 1972 AND 1980 SSI

SCORES. . . . . . . . . . . . . . . . . . . . 36 


\section{CHAPTER I}

\section{INTRODUCTION AND STATEMENT OF PURPOSE}

\section{INTRODUCTION}

Young children between the ages of two and six years often exhlbit part-word, whole word, and phrase repetitions as their language develops. This time period of normal disfluency is also the age range when stuttering most frequently appears. Many parents of disfluent children seek professional help for what they consider or fear to be stuttering. Historically, it has been difficult for speech-language pathologists to determine which children warrant intervention since the normal disfluencies of many young children closely resemble the disfluencies seen in Incipient stutterers. Yet, research has revealed a strong correlation between early identification and successful treatment of stutterers (Panelli, McFarlane, and Shipley. 1978).

Consequently, speech-language pathologists have long needed diagnostic criteria and evaluation tools to distinguish between the incipient stutterer and the normally disfluent child in order to be more definitive in their judgments concerning fluency development. Riley (1972) devised the Stuttering Severity Instrument (SSI) in order to provide an objective measurement of stuttering severity (1972). The SSI continues to be widely used by many speech-language pathologists. The SSI assesses three stuttering parameters: the frequency of sound or syllable repetitions and prolongations, the duration of the stuttering event, as well as physical concomitants associated with the stuttering moment. The SSI also provides a scale for measuring stuttering severity. This severity scale was based upon 
normative data gathered from 109 stuttering children. The levels of severity are determined by comparing the total overall SSI score to the normative data.

However, the severity scale is designed in such a manner that normally disfluent preschool children are often identified as stutterers. There is very limited normattve data of preschool children avallable.

In 1980, Ruley revised the SSI to include the disfluency type single syllable (monosyllabic) word repetition when obtaining the frequency count. The normative data and standardization including monosyllabic word repetitions has not been provided for in the revised SSI. The revised SSI bases the percentlle and severity scores on the 1972 normative data. Consequently, it is questionable whether the SSI is a sufficiently sensitive means to discriminate the fluency differences between the Incipient stutterer and the normally disfluent child.

\section{STATEMENT OF PURPOSE}

The purpose of this investigation is to compare the Stuttering Severity Instrument scores of 10 inciplent stutterers aged two through six years of age, with the scores of 10 nonstutterers matched for sex and age.

The primary question addressed is: Does the SSI discriminate incipient stutterers versus nonstutterers between the ages of two and six? This study will also address the following secondary questions:

1. Do disfluency types not addressed in the SSI (Interjections, revision/incomplete phrases, intrusive schwa, tense pauses, and polysyllabic word repetitions), contribute information which would provide a stronger discrimination between incipient stutterers and normally disfluent children?

2. Do elther the inciplent stutterers or nonstutterers exhibit a significant difference between the SSI scores of the speech samples elicited from picture sequence cards and open-ended questions? 
3. Does the 1972 or 1980 SSI provide a better means of differentially diagnosing the incipient stutterer from the normally disfluent child?

It is hypothesized that the SSI scores identifying children as stutterers will be significantly different from the scores of nonstutterers.

\section{DEFINITION OF TERMS}

The following definitions are to provide the reader with the specifications of the terminology used in this investigation.

dysrhythmic phonation: A type of phonation within a word which disturbs or distorts normal flow of speech which may be attributed to unusual timing or accent, a break, or improper stress. Any disfluency not included in another category will be counted as a dysrhythmic phonation (Williams. Silverman and Kool, 1968).

duration of stuttering: The number of seconds a stuttering event, including any silent or audible prolongations and sound or syllable repetitions, occurs (Riley, 1972).

frequency of stuttering: The number of stuttering events per 100 words of speech (Riley, 1972).

disfluency: Speech which is characterized by interruptions in the flow of speech and is often correlated with an excessive effort in speech production

(Starkweather, 1982). Disfluent speech is not necessarily stuttering and may instead describe childhood developmental hesitations.

incipient stuttering: A child who is exhibiting disfluent speech which is representative of beginning stages of stuttering. The beginning stages of stuttering behavior differ from normal disfluent speech relative to frequency of occurrence, type of discontinuity and/or duration (Adams, 1977; Riley, 1972).

interjection: Extraneous sounds such as "uh", "er", and "hmmm" and extraneous words such as "well", which are distinct from sounds and words associated with the fluent or meaningful text, or with other categorles of nonfluency (Johnson, 1959).

intrusive schwa: A substitution of the schwa for a vowel often found in the syllable being repeated (Adams, 1977).

normal disfluency: Interruptions in the continuity of speech or oral reading which are evident to some degree in the majority of speakers and which do not warrant concern or intervention.

part word repetition: Unintentional repetition of a sound or syllable which is less than the entire word. Includes sound repetitions and syllable repetitions.

Example: "s-s-see" or "ba-ba-ball" (PSU, 1987).

phrase repetitions: Repetition of an utterance of two or more words. Example: "I want, I want to go home." (Johnson, 1959).

physical concomitants: The visible and audible distractions involving excessive effort or tension which a stutterer uses to attempt to force fluent speech while stuttering (Riley, 1972). Riley (1972) lists four categories as physical 
concomitants: 1) distracting sounds (ex. hissing noise, throat clearing), 2) distracting facial grimaces (ex. eye blinks, tongue protrusions), 3) distracting head movements (ex. turning head from listener, head to floor), 4) distracting movements of extremeties (ex. foot tapping arm swinging).

prolongation: The lengthening in time of a speech sound or articulatory posture of the speech mechanism which is of such duration to disrupt the flow of speech or oral reading.

revision/incomplete phrase: The repair of a two or more word phrase which is attributed to a change of thought, a word, or an idea.

Stuttering Severity Instrument (SSI): An objective instrument devised by Glyndon D. Riley, which is used to measure the severity of stuttering based on the three parameters of frequency, duration, and physical concomitants (Riley, 1972).

whole word repetitions: Unintentional repetition of a complete word within an utterance. Includes single syllable and multisyllable words. Example: "ball, ball" or "maybe, maybe".

tense pause: A disfluency that exists between words and nonwords when there are barely audible manifestations of heavy breathing or muscular tightening. The same phenomena within a word would categorize the disfluency as a dysrhythmic phonation (Williams, Silverman, and Kool, 1968). 


\section{CHAPTER II}

\section{REVIEW OF LITERATURE}

The Stuttering Severity Instrument is an objective tool designed to describe stuttering severity behaviors of children and adults (Riley, 1980). It is widely used in the evaluation of children's speech. The administration of the SSI to normally disfluent children results in a stuttering rating (Semler, 1987). For a clinician to provide a confident stuttering diagnosis, a better means for discriminating between the speech of a normally disfluent child and an incipient stutterer may be the types of frequencies of disfluencies not addressed in the SSI (Semler, 1987). It is the intent of this chapter to discuss the characteristics of normally disfluent children and the incipient stutterer, influences of different elicitation procedures when evaluating stuttering, a historical perspective of stuttering evaluation instruments, and a comparison of the 1972 and 1980 Stuttering Severity Instruments.

\section{CHARACTERISTICS OF NORMALLY DISFLUENT CHILDREN}

Haynes and Hood (1977) investigated the speech of 30 male and female children in three chronological age groups comprised of 4-, 6-, and 8-year olds. Speech samples, which contained 50 complete sentences, were gathered in a structured interview situation. These samples were examined for both the quality and quantity of 8 disfluency types. They found that the frequency of specific disfluency types shifted between the age groups. The occurrence of 
interjections was significantly increased between the 4- and 8-year old groups. Whole word repetitions were exhibited more frequently in the 4-year old age group and noticeably decreased with age. Among all 3 age groups, part-word repetitions occurred less than whole word repetitions, revisions and interfections. The results of this study do not support a significant decrease in the total fluency as chronological age increased nor between the sexes.

DeJoy and Gregory's (1985) study of 60 nonstuttering males did show a decrease of total disfluency with chronological age. Thirty of the subjects had a mean age of 3.5 years, while the remaining subjects had a mean age of 5 years. A spontaneous language sample was elicited for each child. The frequency count for nine specific disfluency types were tabulated based on the frequencies per 100 words. The younger subjects evidenced a total disfluency mean of 11.40 per 100 words compared to the 5 year old group which yielded a mean of 9.30 per 100 words. Comparison of the disfluency count for the two age groups revealed higher rates of part word repetitions, word repetitions, phrase repetitions, incomplete phrases and dysrhythmic phonations for the younger subjects. There was not a significant difference between the two age groups for revisions and interjections.

Another study which gathered spontaneous speech samples from normally speaking children was conducted by Yairi (1981). He studied 33 children, 18 females and 15 males, between the ages of 24-33 months who were regarded by their parents and/or investigator as not having a history of stuttering. Results indicated the majority of the children had less than 2 disfluencies per 100 words, with an average total disfluency of 6.50 . Yairi also found over $76 \%$ of the total disfluencies to be comprised of part-word repetitions, single syllable whole word repetitions, interjections, and revisions. When speech samples were arranged in quartiles from the least to the most total 
disfluencies, the result was an increase in all disfluency types from the first quartlle through the fourth except for the polysyllabic word repetitions.

Combined data of both sex groups showed interjections to occur most often, while single syllable word repetitions were the second most common disfluency exhibited.

Wexler and Mysak (1982) investigated the speech of thirty-six 2-, 4-, and 6- year old males for specific disfluency characteristics. The speech samples were obtained with the child conversing with the examiner while playing with a standardized set of toys. The frequency count for the individual disfluency types were compared between the three age levels. Result showed revision/incomplete phrases and interjections to be the most common disfluency type among all three age groups. Part-word repetitions were the least occurring disfluency type for 2- and 4-year olds. The least occurring disfluencies among the 4- and 6-year olds included: dysrhythmic phonations, part-word repetitions, and word repetitions. Wexler and Mysak reported a similar pattern of distribution among disfluency types across all age groups, however the frequency count differs greatly between the ages. The 2-year olds demonstrated a higher frequency count for word and phrase repetitions than the other two age groups. In addition, the 2-year olds revealed a higher frequency count of dysrythmic phonations, $\bar{x}=1.5$, than the 6-year olds who demonstrated a frequency mean of .70 .

More recently, Christianson (1987) conducted an investigation for disfluencies of 20 preschool normal males. Three hundred word speech samples were collected from ten 3 year olds and ten 5 year olds in a structured play situation. Data revealed revision/incomplete phrases were the most frequent occurring disfluency among 3 year olds, followed by whole word repetitions. Among the 5 year old children, interjections, revision/incomplete phrases, word repetitions, and phrase repetitions, in rank order, were found to be the 
most frequent occurring disfluency. The mean total disfluency per 100 words for the 3- and 5- year old groups was 5.47 and 6.87 , respectively.

In another recent study, Semler (1987) investigated the frequencies of specific types of disfluencies exhibited in twenty 33-39 month old normal children, 10 females and 10 males. The children in this investigation exhibited more whole word repetitions, revision/incomplete phrases and interjections than any other type of disfluency. Results indicate whole word repetitions to be the most frequent disfluency type among both groups, $x=1.50$. The least occurring disfluency for both groups was dysrhythmic phonations, tense pauses and part word repetitions. The total number of disfluencies per 100 words was found to be 6.35. Refer to Table I for a comparison of researchers' findings on normal disfluencies.

\section{CHARACTERISTICS OF INCIPIENT STUTTERERS}

Certain disfluency types appear to provide a distinction between the speech of an incipient stutterer and the normally disfluent chlld. Research shows more part-word repetitions and prolongations in the speech of incipient stutterers (Andrews et al., 1982: Starkweather, 1982). The only published study evaluating disfluency distributions in groups of stutterers and nonstutterers revealed two distinctive population samples (Yairi and Lewis, 1984). Yairi and Lewis obtained speech samples from ten 2- and 3-year old children who were diagnosed by their parents to have been stuttering for two months or less. These ten subjects were matched with normal speaking subjects. The speech samples of both groups were compared. Part word repetitions were the most frequently occurring disfluency type for the stuttering group with a mean of 6.99. Dysrhythmic phonations and single syllable word repetttions followed with means of 5.21 and 3.57 respectively. The three most frequent disfluencies for 


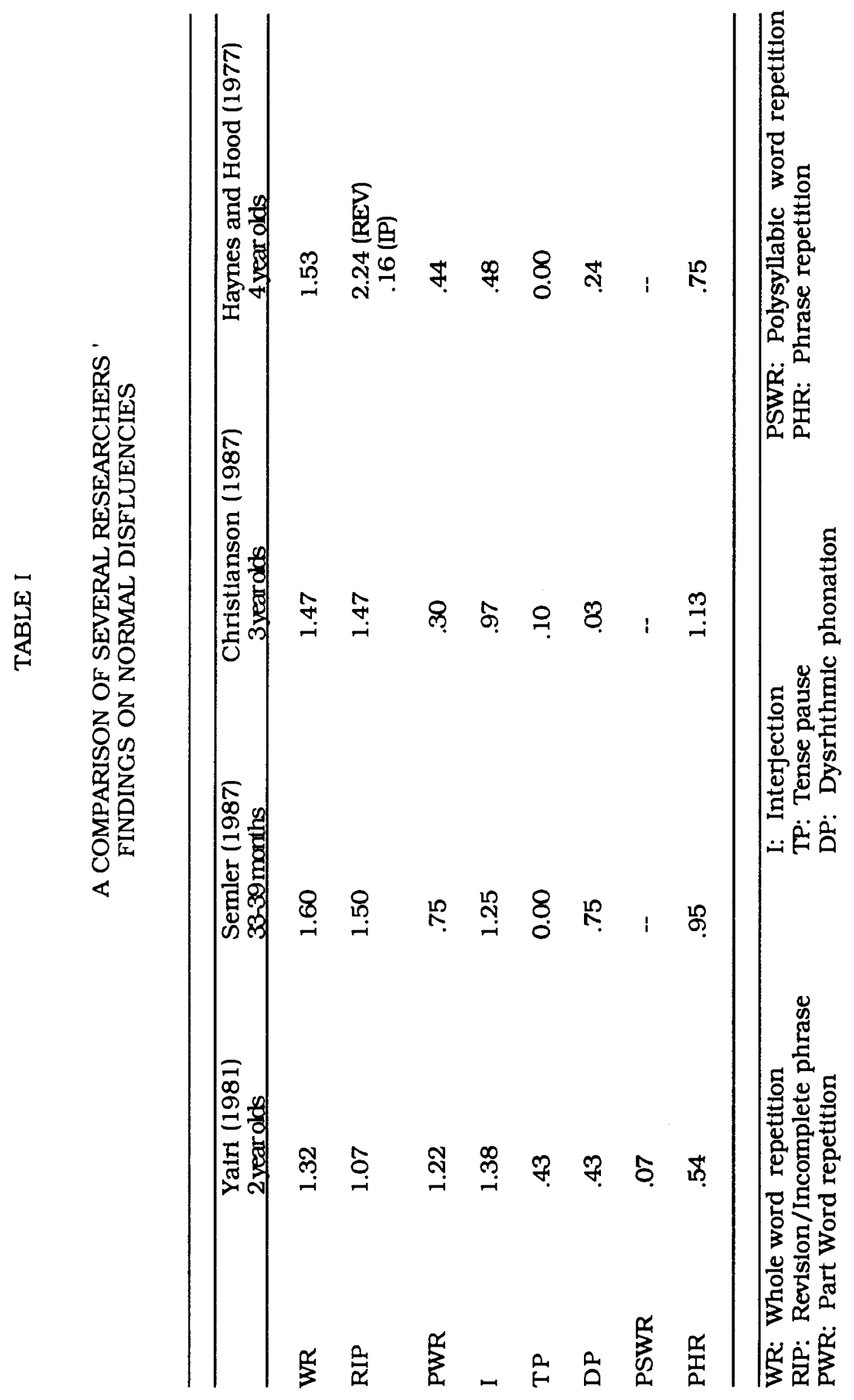




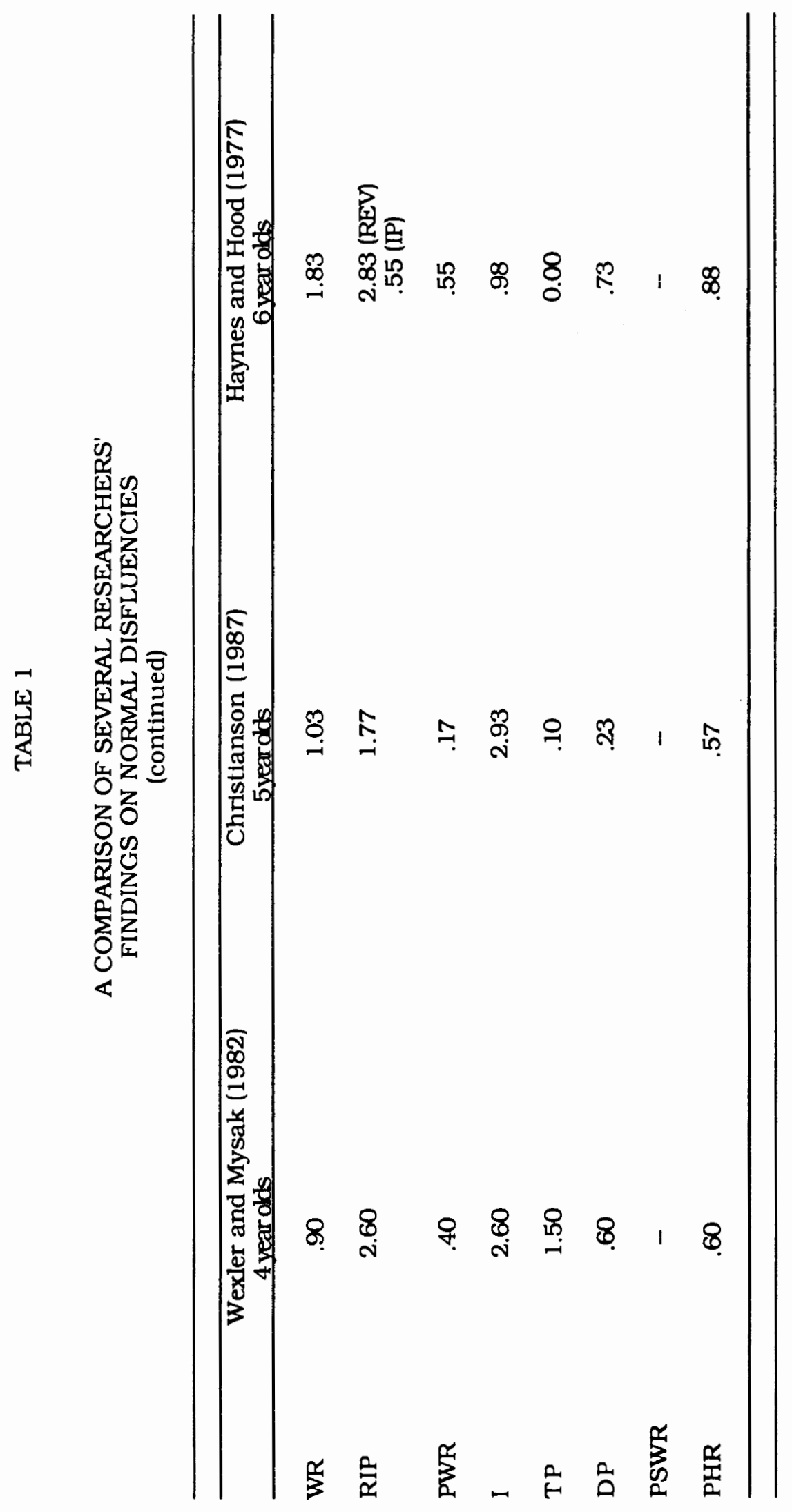


the control group were interjections, part-word repetitions, and revision/incomplete phrases. The total number of disfluencies per 100 syllables demonstrated by the individual stutterers ranged from $6.51-46.79$, with a stuttering group mean of 21.54 per 100 syllables. Data revealed the nonstuttering group to exhibit a mean of 6.16 total disfluencies per 100 syllables, thus making the experimental group three and a half times more disfluent.

Although studies are very limited in the comparison of the speech of preschool stutterers and nonstutterers, some researchers have developed differential diagnosis guidelines based upon past literature (Adams, 1977; Pindzola and White, 1986). A higher frequency of part word repetitions and prolongations were found to be indicative of incipient stutterers (Adams, 1977; Riley, 1972; Yatri and Lewis, 1984). The presence of physical concomitants, visible and audible struggle behaviors, often accompany the disfluencies of stutterers (Pindzola and White, 1986; Riley, 1972). Incipient stutterers also tend to demonstrate disfluent speech at least 10 percent of the time (Adams, 1980).

\section{INFLUENCE OF ELICITATION PROCEDURES ON STUTTERING EVALUATIONS}

Most investigations do not consider the influence of communicative stresses when gathering speech samples to analyze for disfluencies. DeJoy and Gregory (1985) suggest that the environment may have a great effect on the evaluation of children's disfluencies. Wexler (1982) conducted a study to obtain more information about the influences of environmental stimuli. This study was designed to look at the quantitative and qualitative data of disfluency types among 36 nonstuttering males aged 2-, 4-, and 6 -years old in two different situations, one neutral and one stress situation. The neutral situation was that 
In which the child played with a standardized set of toys in a playroom with the investigator. The child was able to take the conversational lead in this situation and the investigator avolded the use of communicative stress factors (i.e., interruptions, noise, questioning). In contrast, the stress situation utllized the same play routine with the investigator providing frequent verbal communicative stressors to the interaction. These stressors were not contingent on the child's disfluency. When comparing the effects of stress on the frequency of disfluency types there was a statistically significant difference in the neutral situation for word repetitions and phrase repetitions. The 2-year olds demonstrated a mean of 2.11 for word repetitions, and 2.18 for phrase repetitions in the neutral situation as compared to 1.34 and 1.42 in the stress situation. In the stress situation, the 2-year olds demonstrated a higher frequency of repetitious units per disfluency (oscillations) than either of the other age groups. The younger age group also had a significantly higher frequency count of dysrhythmic phonations than the six year olds. In Wexler's study, the disfluency difference between the two situations occur with the mean of specific disfluency types and not overall disfluency production.

Silverman (1972) also reported on the disfluencies of preschool children In two different speaking situations. She obtained speech samples from ten 4year old boys in a free play activity at their preschool and in a structured interview. Silverman collected frequency and duration data for the disfluencies observed in six speech samples per subject. In both situations, the disfluency types and the number of units per disfluency were comparable. However, there was a situational difference regarding the total number of disfluencies. The subjects were found to be more disfluent during the structured interview situation. 
Although data supporting the effect of elicitation procedures is limited, there does appear to be some influence on a child's disfluency types and the frequency of disfluencies (Silverman, 1972; Wexler, 1982). Speech samples gathered by a structured interview may not be representative of a child's speech In a natural situation (Silverman, 1972).

\section{HISTORICAL PERSPECTIVE OF EVALUATION METHODS}

Previous stuttering evaluation instruments, such as scales and selfreports, provided the clinician with a weak estimate of the severity level. The Iowa Scale for Rating the Severity of Stuttering (Johnson, Darley, Spriesterbach, 1963) provides a rough estimate of stuttering severity by using a zero to seven point descriptive value score to rank the severity of disfluencies. The 7 point scale items are described as: 1) no stuttering; 2) stuttering on $2 \%$ of words; 3 ) stuttering occurs on $2-5 \%$ of the words with the majority of blocks not lasting longer than a full second; 4) $5-8 \%$ of the words are disfluent with an occasional facial grimace; 5) disfluencies occur on $8-12 \%$ of words with blocks averaging 2 seconds; 6) obvious facial grimaces and extremity movements are present and approximately $12-25 \%$ of the words are disfluent; 7) stuttering is very severe with over $25 \%$ of words being disfluent accompanied with severe physical concomitants.

In 1972, Riley attempted to objectify Johnson's Iowa scale by developing the SSI. The SSI was designed to evaluate the stuttering severity of both children and adults. Riley took into account 3 parameters when developing the SSI. These parameters are: frequency of repetition and prolongation of sounds and syllables, estimation of duration, and the observable physical concomitants. 
Another method used to evaluate disfluent children was presented by Adams (1977). He developed differential diagnostic criteria based upon past research. The 5 criteria include information regarding the child's disfluencies, Including specific disfluency types, frequency and the number of oscillations. The following are the spectfic guidelines used to differentiate the incipient stutterer from the normally disfluent child: the incipient stutterer exhibits 10 or more disfluencies per 100 words; part word repetitions, prolongations and broken words are the predominate disfluency types of incipient stutterers; the intrusive schwa is present in the part word repetitions of incipient stutterers; incipient stutterers produce at least 3 unit repetitions; and the incipient stutterer demonstrates effortful disfluencies, often of longer duration whereas, the normally disfluent child demonstrates effortless disfluencies and maintains a continuous volcing or airflow between the repetitious units. If a child meets 4 or more of these criteria of either category a more confident diagnosis can be made. However, if a child demonstrates 2 or 3 behavioral criteria from each group Adams suggests monitoring the child's fluency closely.

Pindzola and White (1986) also developed an appraisal instrument based upon past data. Unlike Adams, their protocol was designed to incorporate physical concomitants and psychological variables in addition to the quantitative information regarding the child's disfluencies. The protocol provides the clinician with a grid in which to categorize the child's speech as normal, questionable, or indicative of stuttering. Like Adams (1977), if a child's speech includes some questionable behaviors, it is suggested to monitor the fluency problem. 
COMPARISONS OF THE 1972 AND 1980

STUTTERING SEVERIY INSTRUMENTS

Glyndon D. Riley recognized the need to collectively quantify and describe stuttering severity in an objective manner. Consequently, in 1972 Riley designed the SSI to evaluate the stuttering severity of children and adults. The SSI was designed to meet the following 6 criteria:

1. It must be simple enough to be utilized in any reasonable clinical setting by a trained clinician.

2. It must be as objective as possible.

3. It must be sensitive enough to determine changes in severity which are clinically signfficant even If the change in severity is not apparent to the untrained observer.

4. The statistical characteristics must be applicable for clinical and research use.

5. Normative data must be available so that any disfluent speech sample can be placed on a standardized severity scale.

6. The test should be useful in making judgments of both children and adult speech behaviors.

Riley took into account three parameters when developing the SSI.

These parameters are: frequency of repetition and prolongation of sounds and syllables, estimation of duration of the three longest blocks, and observable physical concomitants. These three categories were chosen because they met the criteria of observability and measurability.

SSI administration procedures differ among children depending on their reading level. If a child is below a third grade reading ability then a cartoon 
sequence is recommended to elicit a speech sample. The speech samples are analyzed for frequency, duration, and physical concomitants. In order to complete a frequency count a sample of 150 words is required, with the first and last 25 words not contributing to the percentage score. In order to obtain a duration score, the three longest blocks must be averaged together. The visual behaviors noticed during a block or an attempt to avold blocking are scored in the area of physical concomitants. Both the duration and physical concomitant scores are drawn from the entire 150 word sample. The raw scores for each of the three parameters are converted to points or a task score. Task scores range from $0-45$. It is the overall task score which is compared to the severity conversion chart in order to obtain a descriptive severity level (mild, moderate, severe, etc.).

When obtaining a frequency count using the 1972 SSI procedures, whole word repetitions, phrase repetitions, and rephrasing were not considered as disfluencies. Only silent or audible prolongations and sound or syllable repetitions were identified as disfluencies. However, in 1980 Riley revised the SSI to include monosyllabic whole word repetitions in the frequency count. This particular disfluency type is known to be characteristic of normally disfluent children (Christianson, 1987; Haynes and Hood, 1977; Semler, 1987; Yairi, 1981). The normative data and standardization including the monosyllabic word repetitions in the SSI procedure is not provided in the 1980 publication. Instead the severity conversion table for the 1980 SSI is based upon the 1972 normative data.

The SSI conversion table consists of percentile levels which are based on stanine scores (Riley, 1988). These percentile levels were assigned five severity labels; very mild, mild, moderate, severe, very severe. The 1972 severity conversion chart did not clearly delineate which percentile levels were to be assigned to a particular descriptive label. In the 1980 version, the severity 
equivalents are clearly defined. The 1972 severity chart is misleading because Riley did not provide lines to delineate which percentile levels correspond with the severity labels. See Tables II and III for a comparison of the 1972 and 1980 SSI Severity Conversion chart.

Despite its limitations, the SSI is a widely used instrument. One must consider that the 1980 SSI is more likely to rank normally disfuent children higher on the stuttering severity rating since monosyllabic word repetitions are counted and then compared to the normative data omitting monosyllabic word repetitions. Further research is needed to provide speech-language pathologists guidelines for diagnosing the inclpient stutterer from the normally disfluent child. The 1980 SSI was chosen for this present study because it is the publication most commonly used for clinical and research purposes today. 
TABLE II

1972 SSI SEVERTY CONVERSION TABLE FOR NONREADERS

\begin{tabular}{ccl}
\hline Total Overall Score & Percentile & Score \\
\hline $0-5$ & $0-4$ & \\
$6-8$ & $5-11$ & very mild \\
$9-13$ & $12-23$ & \\
$14-15$ & $24-40$ & \\
$16-19$ & $41-60$ & \\
$20-23$ & $61-77$ & \\
$24-27$ & $78-89$ & severe \\
$28-30$ & $90-96$ & \\
$31-45$ & $97-100$ & very severe
\end{tabular}

TABLE III

1980 SSI SEVERITY CONVERSION TABLE FOR NONREADERS

\begin{tabular}{lll}
\hline & & \\
\hline Total Overall Score & Percentile & Score \\
\hline $0-5$ & $0-4$ & vervmild \\
\hline $6-8$ & $5-11$ & \\
$9-13$ & $12-23$ & mild \\
$14-15$ & $24-40$ & \\
\hline $16-19$ & $41-60$ & moderate \\
$20-23$ & $61-77$ & \\
& & \\
\hline $24-27$ & $78-89$ & severe \\
$28-30$ & $90-96$ & very severe \\
\hline $31-45$ & $97-100$ & \\
\hline
\end{tabular}




\section{CHAPTER III}

\section{METHODS}

Two groups of subjects were used in this study: one containing ten children,between the ages of two and six who are identified as stutterers by their primary caretaker, and the second containing ten nonstuttering children matched by age and sex of the stuttering subjects. The subjects, both the experimentals and controls, ranged in age from 2 years, 6 months to 5 years, 10 months with a mean of 4.4 years for both groups. The subjects consisted of 18 males and 2 females. These children were selected from day care centers and personal contacts in the Portland metropolitan area. Subject selection required all children to meet the following criteria:

1. Speech intelligibility of 75 percent and a mean length of response (MLR) of at least 2.5;

2. No prior direct intervention for fluency;

3. No history of chronic middle ear infections or reported hearing loss;

4. No history of developmental delay, retardation neurological or physical impairment;

5. Spoke English as the primary language in the home. 


\section{SUBJECT ELIGIBILITY PROCEDURES}

A letter explaining the purpose of this study (Appendix A), a parent permission form (Appendix B), and an eligibility questionnaire (Appendix C) were distributed to parents at day care centers and to personal contacts within the Portland metropolitan area. Subject eligibility was based upon the information obtained in the eligibility questionnatre. A questionnaire concerning the child's genetic speech and medical development was completed by the parent. The children were identified as "high risk" if the parent or primary caregiver positively answered one or more questions within the stuttering section of this questionnaire, while the "low risk" children were selected if all the questions in the stuttering section were answered negatively. A telephone conversation which provided the parent with the purpose of this investigation preceded the completion of the parent permission form.

Once the permission forms were signed by the parent and the children met the eligibility requirements addressed in the eligiblity questionnaire, the children participated in procedures and intelligibility was determined by eliciting a 100 word speech sample at their home or preschool or prior to videotaping. The investigator felt comfortable in the identification of the subjects for both populations. For future research purposes, the Peabody Picture Vocabulary Test-Revised (Form M) was administered to each child.

\section{SPEECH SAMPLE PROCEDURES}

Speech samples of 300 words were elicited from each subject. The subjects completed the speech samples in a quiet clinic room with a one-way mirror at the PSU Speech and Hearing Sciences Clinic. In one segment, a 150 word speech sample was elicited by cartoon (sequencing) pictures. The other 150 
word segment was elicited by open-ended questions (See Appendix D for a list of stimuli). In both segments the investigator is interacting with the child. The video camera/recorder was placed behind the one-way mirror that adjoined the clinic room. A graduate student or speech-language pathologist trained in the operation of the video equipment, recorded the speech samples.

Two 150 word segments were transcribed for each of the subjects' videorecorded speech samples. Following transcription each segment was analyzed using two methods: 1) The Stuttering Severity Instrument and 2) coding specific types of disfluencies not accounted for on the SSI. Each transcribed 150 word segment was then analyzed to determine the subject's frequency score, duration score, physical concomitant score, and total overall severity score utilizing the scoring procedure outlined in Riley's Stuttering Severity Instrument. Refer to Appendix E.

Upon completion of the SSI, each transcript was then analyzed for specific disfluency types. These specific disfluency types included: phrase repetitions, whole word repetitions of more than one syllable, interjections, revision/incomplete phrases, intrusive schwa and tense pauses. The coded symbol for each disfluency type (see Appendix $F$ for coded symbol of disfluency types) was written above the corresponding disfluency on the transcript. The frequency count for each of these disfluency types was tabulated for each of the transcribed segments. 


\section{RELIABILITY}

To determine investigator reliability in the administration of the SSI, six 150 word samples, 3 samples from each elicitation procedure were randomly selected (Appendix G, Instructions for Administration of the SSI for Reliability Testing). Two speech-language pathologists who were trained in the use of the SSI from Portland State Untversity Department of Speech and Hearing Sciences were then provided with a tracking form (Appendix $\mathrm{H}$ ). A speech-language pathologist not familiar with the particular video recordings chose the segments to be analyzed.

The interpretation of the SSI interjudge reliabllity for task scores and severity ratings are presented in Table IV.

TABLE IV

TEST SCORES AND SEVERITY RATINGS FOR SIX SUBJECTS FOR EACH OF THE THREE JUDGES Judge 1 Juxdee 2 Judge 3

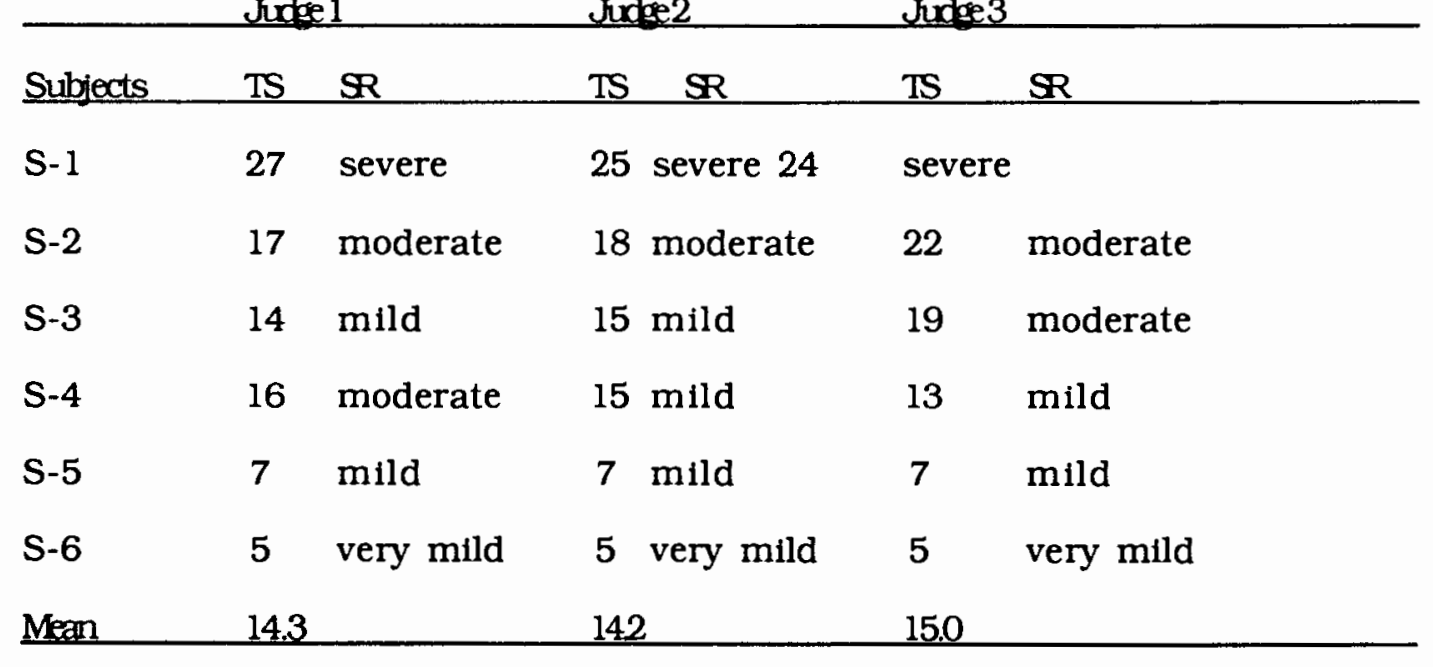


The percentage of SSI scores within a given stanine were also analyzed. The percentage of interrater agreement of SSI scores are shown in Table V.

TABLE V

PERCENTAGE OF INTERRATER AGREEMENTS OF SSI SCORES FOR EACH OF THE THREE JUDGES

Percentile Apreement Judges 182 Judges 2 \& 3 Judges $1 \& 3 \quad$ Combined Identical $83 \%$ $50 \%$ $50 \%$ $50 \%$ $\pm+1$ $100 \%$ $100 \%$ $83 \%$ $899 \%$ $++-2$ $100 \%$ $100 \%$

SSI intrajudge reliability was determined be scoring two identical 150 word segments one week later. A comparison of test scores and severity ratings for the two subjects by each of the judges are shown in Table VI.

\section{TABLE VI}

INTRAJUDGE RELIABILITY OF SSI TEST SCORES AND SEVERITY RATINGS

Subject 1

Test 1

Test 2

Subject 2

\begin{tabular}{|c|c|c|c|c|c|c|c|c|}
\hline \multirow[b]{2}{*}{ suxge } & \multicolumn{2}{|c|}{ Test 1} & \multicolumn{2}{|c|}{ Test 2} & \multicolumn{2}{|c|}{ Test 1} & 2 & \multirow[b]{2}{*}{$\mathbf{R}$} \\
\hline & TS & $\mathbf{S R}$ & TS & $\mathbf{S R}$ & TS & $\mathbb{R}$ & IS & \\
\hline $\mathrm{J}-1$ & 7 & mild & 6 & mild & 24 & severe & 26 & severe \\
\hline $\mathrm{J}-2$ & 6 & mild & 7 & mild & 25 & severe & 25 & severe \\
\hline $\mathrm{J}-3$ & 7 & mild & 8 & mild & 24 & severe & 23 & moderate \\
\hline
\end{tabular}

To determine the investigator reliability for identifying disfluency types (Appendix I), ten randomly selected utterances from each of the six samples used for the SSI reliability were analyzed for specific disfluency types. The 
technician who randomly selected the video recordings for reliabllity also provided reliability raters with basic content transcripts (Appendix J). For the purpose of this study, a basic content transcript is defined as the basic information of the child's utterance, deleting any type of disfluency, such as; phrase repetitions, part-word repetitions and interjections. The technician then showed the reliability raters all ten utterances at once while the raters observed the episodes in their entirety. The videotaped segments were then vlewed again with one episode being rated at a time. Having been trained in a prior session, the reliability raters were responsible for providing all the missing parts of the transcript, deleted words and all disfluencies.

A percentage of accuracy was calculated to determine interjudge and intrajudge reliability for identifying disfluency types. The agreement index for interjudge reliability was 88 percent.

Intrajudge reliability was determined one week later. It was 100 percent for all three judges.

\section{Data Analysis}

Data analysis included a comparison between the SSI scores for both "high risk" and "low risk" preschool children. Since the SSI yields a single numerical representation of severity within a range of $0-45$, the level of measurement is descriptive. Therefore, to determine the significant difference between these two populations a Mann-Whitney U test was used. Additionally, a t-test was used to determine the correlations between the disfluency types of the two populations. 


\section{CHAPTER IV \\ RESULTS AND DISCUSSION}

\section{RESULTS}

The purpose of this study was to determine if the Stuttering Severity Instrument differentially diagnoses incipient stutterers from the normally disfluent children between the ages of two and six years. Speech samples were assessed with the SSI and disfluency types were analyzed. The specific disfluency types analyzed were the following: 1) part-word repetitions, 2) dysrhythmic phonations, 3) monosyllabic whole word repetitions, 4) interjections, 5) polysyllabic word repetitions, 6) phrase repetitions, 7) revision/incomplete phrases, 8) tense pauses, and 9) the intrusive schwa. The frequencies of these disfluency types were compared between the two populations. The findings of this investigation will be reported to answer the primary and secondary questions stated in Chapter I.

\section{Questions}

Does the SSI discriminate incipient stutterers from nonstutterers between the ages of 2 and 6 ?

The Mann-Whitney U test (Siegel, 1956) was selected because this study used two independent groups of a small sample size. The U-value was determined to be 3 , with a $\mathrm{p}$ value of .0014 , indicating a statistically significant difference between the group SSI scores of the incipient stutterers and normally disfluent children at the .002 level of significance.. 
The SSI results, including the total score, stuttering severity rating, and percentile level are presented in Table VII. Table VII shows the scores of stuttering subjects number $2,7,8$, and 10 as overlapping with the scores of three control subjects. Results show that even though the SSI discriminates between the two groups, it does not provide a reliable means for discriminating at an individual level. Normally disfluent children were labeled as stutterers according to the SSI. The experimental group demonstrated 3 mild, 6 moderate and 1 severe ranking.

Do disfluency types not addressed in the SSI contribute information which would provide a stronger discrimination between incipient stutterers and normally disfluent children?

The disfluency types, polysyllabic word repetitions, tense pauses, intrusive schwas, and revision/incomplete phrases, provide information which may be helpful in differentially diagnosing disfluency in children. However the disfluency types of phrases repetitions and interjections did not provide information for a clearer means of discriminating between the incipient stutterer and normally disfluent children. A one-talled t-test was used to determine the correlations between the subjects and controls in regards to disfluency types. The mean scores for the disfluency types were also tabulated for comparison between the two populations.

The data revealed a statistically significant difference between the two groups for polysyllabic word repetitions, intrusive schwas, tense pauses and revision/incomplete phrases. Polysyllabic word repetitions with a $\mathrm{t}$-value of 5.00 and tense pauses with 4.33 were both statistically significant at the .0005 level of confidence. A t-value of 1.81 for revision/incomplete phrases revealed a statistically significant difference at the .05 level of confidence. A t-value of 
TABLE VII

A COMPARISON OF THE 1980 SSI SCORES FOR STUTTERERS AND NONSTUTTERERS BETWEEN THE AGES OF 2 THROUGH 6 YEARS

\begin{tabular}{|c|c|c|c|}
\hline & SSi Soare & Percentile & $\begin{array}{l}\text { Severity } \\
\text { Ranking }\end{array}$ \\
\hline Subject 1 & 21 & $61-77$ & Moderate \\
\hline Subject 2 & 13 & $12-23$ & Mild \\
\hline Subject 3 & 20 & $61-77$ & Moderate \\
\hline Subject 4 & 14 & $24-40$ & Mild \\
\hline Subject 5 & 24 & $78-89$ & Severe \\
\hline Subject 6 & 20 & $61-77$ & Moderate \\
\hline Subject 7 & 16 & $41-60$ & Moderate \\
\hline Subject 8 & 18 & $41-60$ & Moderate \\
\hline Subject 9 & 14 & $24-40$ & Mild \\
\hline Subject 10 & 16 & 41-60 & Moderate \\
\hline Control 1 & 16 & $41-60$ & Moderate \\
\hline Control 2 & 8 & $5-11$ & Mild \\
\hline Control 3 & 0 & $0-4$ & Very Mild \\
\hline Control 4 & 7 & 5-11 & Mild \\
\hline Control 5 & 16 & $41-60$ & Moderate \\
\hline Control 6 & 5 & $0-4$ & Very Mild \\
\hline Control 7 & 6 & $5-11$ & Mild \\
\hline Control 8 & 10 & $12-23$ & Mild \\
\hline Control 9 & 7 & 5-11 & Mild \\
\hline Control 10 & 2 & $0-4$ & Very Mild \\
\hline
\end{tabular}


1.88 for intrusive schwas was also found to be statistically significant at the .05 level of confidence for both disfluency types.

A t-value of 1.32 for phrase repetitions and .42 for interjections found these disfluency types not to be significant at the. 05 level of probability. The tscores are displayed in Table VIII.

The most frequently occurring disfluency type for the experimental group was part-word repetitions with a mean of 4.80 . For the control group, part-word repetitions were one of the least occurring disfluency types with a mean of .45. Monosyllabic whole word repetitions closely followed with a mean of 4.40 for the experimental subjects. Interjections were the most frequently occurring disfluency type for the controls with a mean of 1.45 followed by monosyllabic whole word repetitions with a mean of .95 . A mean of 4.00 was found for the stuttering group in regards to interjections.

The means and standard deviations of specific disfluency types were tabulated for both the stutterers and nonstutterers. A comparison of the disfluency means, standard deviations and rank orders are presented in Table IX. Both groups produced tense pauses and intrusive schwas more frequently than polysyllabic word repetitions. The stuttering subjects had a mean of 65 for both tense pauses and the intrusive schwa. Whereas the controls produced a mean of .15 and .20 for tense pauses and the intrusive schwa, respectively. The least frequent disfluency type for both populations was polysyllabic word repetitions with a mean of .10 for the experimental group and 0.00 for the control group.

Phrase repetitions in the speech of the stutterers were demonstrated at a mean of 1.25 versus .40 for the controls. Revision/incomplete phrases occurred slightly less often than phrase repetitions with a mean of 1.10 for the experimental group as compared to .45 for the controls. 
TABLE VIII

\section{RESULTS OF A ONE-TAILED T-TEST FOR UNRELATED MEANS COMPARING THE DISFLUENCY TYPES NOT ADDRESSED IN AND NONSTUTTERERS}

Disfluency Type Mean Degree of Freedom T.Scare

Polysyllablc word Repetitions

(S) .10

18

Polysyllabic word Repetitions

(C) 0.00

(S) 1.25

18

(C) .40

18
$5.00^{* *}$

18
Phrase Repetitions

Revision/Incomplete

Phrases

(S) 1.10

18

Revision/Incomplete Phrases

(C) .50

18

Tense Pause

(S) .65

18

Tense Pause

(C) .15

18

\section{$4.33^{* *}$}
Intrusive Schwa
(S) .65
18
Intrusive Schwa
(C) .20
18

$\begin{array}{lll}\text { Interjections } & \text { (S) } 4.10 & 18 \\ \text { Interjections } & \text { (C) } 1.45 & 18\end{array}$

$1.88^{*}$

$\mathrm{S}=$ Stutterers

$\mathrm{C}=$ Controls

* Significant at the .05 level

** Significant at the .0005 level 
TABLE IX

A COMPARISON OF THE MEANS, STANDARD DEVIATIONS AND RANKINGS FOR SPECIFIC DISFLUENCY TYPES FOR STUTTERERS AND NONSTUTTERERS

Experimental Disfluencles

1. PWR

2. MSWR

3. INT

4. DP

5. PHR

6. RIP

7. TP

8. IS

9. PSWR
Means

Standard Deviations

Control

Disfluencies

4.26

1. INT

3.59

2. MSWR

5.28

3. RIP

4. PWR

5. DP

6. PHR

7. IS

8. TP

9. PSWR

1.23

.93

.10

.31
Means

1.45

.95

.50

.45

.45

.40

Standard Deviations

2.37

1.54

.76

1.00

.76

.60

.20

.52

.15

.49

0.00

0.00 
There was a great difference between the means for dysrhythmic phonations. The stuttering group exhibited dysrhythmic phonations with a mean of 2.65 as compared to .25 for the control group. Prolongations accounted for 2.15 of the mean for dysrhythmic phonations.

The disfluency types of revision/incomplete phrases, polysyllabic word repetitions , tense pauses, and intrusive schwas were the only two disfluency types which statistically provided information which may contribute to a stronger discrimination between the two sample populations.

Does either the incipient stutterers or nonstutterers exhibit a significant difference between the SSI scores of the speech sample elicited from picture sequence cards versus open ended questions?

When looking only at disfluency types included in the SSI assessment, neither sample population exhibited a significant difference between the two elicitation procedures used to elicit speech samples. The $p$ value for incipient stutterers was determined to be .76 whereas the control subjects had a $\mathrm{p}$ value of .23 indicating that neither group exhibited a significant difference beyond the .05 level of confidence. A comparison of the SSI scores for both elicitation procedures is provided in Table $\mathrm{X}$.

Upon comparison of the means and standard deviations of all disfluency types between the two elicitation procedures, the stuttering subjects produced a total disfluency count of 19.40 as compared to 2.60 for the control subjects during the play situation. The picture elicitation procedure resulted in a total disfluency count of 20.10 and 6.20 for stutterers and nonstutterers respectively. The picture stimuli elicited an increase in all disfluency types for nonstutterers and stutterers, with a slightly larger difference for nonstutterers. Refer to Table XI and XII for a comparison of specific disfluency types between the two elicitation procedures. 
TABLE X

A COMPARISON OF THE SSI SCORES FOR PICTURE AND PLAY ELICITATION PROCEDURES

Picture Elicitation

Play Elicitation

\section{Age} SSI Scores SSI Scores

Subject 1

4.10

21

17

Subject 2

4.10

13

5

Subject 3

4.5

20

20

Subject 4

5.1

14

5

Subject 5

3.6

24

19

Subject 6

3.3

20

18

Subject 7

5.91

16

20

Subject 8

2.6

18

18

Subject 9

3.9

14

20

Subject 10

5.10

16

15

SSI Mean

17.6

15.7

Control 1

3.4

16

8

Control 2

4.5

8

7

Control 3

3.6

0

7

Control 4

5.0

7

16

7

Control 5

5.6

5

7

Control 6

3.5

0

Control 7

5.3

6

0

Control 8

5.0

10

0

Control 9

5.10

7

7

Control 10

2.6

2

2

SSI Mean

7.7

4.5 
TABLE XI

\begin{abstract}
A COMPARISON OF THE MEANS AND STANDARD DEVIATIONS OF DISFLUENCIES FOR STUTTERERS AND NONSTUTTERERS IN A PLAY ELICITATION
\end{abstract}

\begin{tabular}{lccll} 
& $\begin{array}{c}\text { Experimental } \\
\text { Means }\end{array}$ & $\begin{array}{l}\text { Standard } \\
\text { Deviation }\end{array}$ & $\begin{array}{l}\text { Control } \\
\text { Means }\end{array}$ & $\begin{array}{l}\text { Standard } \\
\text { Deviation }\end{array}$ \\
\hline PWR & 4.70 & 3.77 & .40 & .70 \\
DP & 3.30 & 3.38 & .20 & .42 \\
MSWR & 3.50 & 3.81 & .40 & .84 \\
INT & 5.20 & 7.21 & .90 & .88 \\
PSWR & 0.00 & 0.00 & 0.00 & 0.00 \\
PHR & 1.00 & 1.89 & .20 & .42 \\
RIP & .90 & .99 & .30 & .68 \\
TP & .10 & .32 & .20 & .63 \\
IS & .70 & .95 & 0.00 & 0.00 \\
TOTAL & 19.40 & 13.58 & 2.60 & 2.07 \\
\hline
\end{tabular}

PWR: Part word repetitions DP: Disrhythmic phonations MSWR: Monosyllabic word repetitions INT: Interjections PSWR: Polysyllabic word repetitions
PHR: Phrase repetitions RIP: Revision/Incomplete phrases TP: Tense pause

IS: Intrusive schwa 
TABLE XII

A COMPARISON OF THE MEANS AND STANDARD DEVIATIONS OF DISFLUENCIES FOOR STUTTERERS AND NONSTUTTERERS IN A PICTURE ELICITATION

Experimental Means
4.90

2.00

5.40

3.00

.20

1.50

1.51

1.34

1.55

.97

10.26

20.10

TOTAL

.60

.40

6.20

6.29
PWR: Part word repetitions

DP: Disrhythmic phonations

MSWR: Monosyllabic word repetitions

INT: Interjections

PSWR: Polysyllabic word repetitions
PHR: Phrase repetitions

RIP: Revision/Incomplete phrases TP: Tense Pause

IS: Intrusive Schwa 
Does the 1972 or 1980 SSI provide a better means of differentially diagnosing the incipient stutterer from the normally disfluent child?

Neither the 1972 or 1980 versions of the SSI provided a better means of discriminating between the inciptent stutterers and the normally disfluent children. The 1980 SSI differentially dragnosed the incipient stutterers from the normally disfluent children with a p value of .0038; whereas, the 1972 version discriminated at a $p$ value of .0037 . Both of these $p$ values are significant at the .05 level of confidence. Table XIII compares the 1972 and 1980 SSI scores, percentile rankings, and severity levels for experimental subjects.

\section{DISCUSSION}

The major question addressed in this study is whether or not the SSI discriminates between incipient stutterers and nonstutterers between the ages of 2 and 6. The analysis of the present data revealed that the SSI does discriminate between the groups of incipient stutterers and normally disfluent children. However, the SSI does not appear to be a good means of discriminating between individual subjects. In this study, the SSI labeled normally disfluent chlldren as very mild, mild, and moderate stutterers. Two of the control subjects had moderate severity rankings. It is possible that one of the two subjects may be "at risk" for stuttering. The present study also supports that data revealed in Semler's (1987) study. Semler studied twenty normally disfluent children 33-39 months of age and found all subjects were labeled by the SSI as very mild or mild stutterers. Of course, with this instrument there is no way to escape the label of at least a very mild stutterer.

The SSI appears to not only label normally disfluent children as stutterers, but also results in scores which overlap between the two sample populations. The overall severity scores and ratings do differentiate between most subjects. However, three of the overall scores and rankings for the 
TABLE XIII

A COMPARISON OF THE 1972 AND 1980 STUTTERING

SEVERITY INSTRUMENT SCORES

\begin{tabular}{|c|c|c|c|c|c|c|}
\hline & $\begin{array}{l}1972 \text { SSI } \\
\text { Socres }\end{array}$ & $\%$ & $\begin{array}{l}\text { Severity } \\
\text { Ramking }\end{array}$ & $\begin{array}{l}1980 \text { SSI } \\
\text { Socres }\end{array}$ & $\%$ & $\begin{array}{l}\text { Severity } \\
\text { Ranking }\end{array}$ \\
\hline Subject 1 & 21 & $61-77$ & Moderate & 21 & $61-77$ & Moderate \\
\hline Subject 2 & 9 & $12-23$ & Moderate & 13 & $12-23$ & Mild \\
\hline Subejct 3 & 18 & $41-60$ & Moderate & 20 & $61-77$ & Moderate \\
\hline Subject 4 & 14 & $24-40$ & Moderate & 14 & $24-40$ & Mlld \\
\hline Subject 5 & 22 & $78-89$ & Severe & 24 & $78-89$ & Severe \\
\hline Subject 6 & 20 & $61-77$ & Moderate & 20 & $61-77$ & Moderate \\
\hline Subject 7 & 14 & $24-40$ & Moderate & 16 & $41-60$ & Moderate \\
\hline Subject 8 & 18 & $41-60$ & Moderate & 18 & $41-60$ & Moderate \\
\hline Subject 9 & 12 & $12-23$ & Moderate & 14 & $24-40$ & Mild \\
\hline Subject 10 & 14 & $24-40$ & Moderate & 16 & $41-60$ & Moderate \\
\hline Control 1 & 16 & $41-60$ & Moderate & 16 & $41-60$ & Moderate \\
\hline Control 2 & 8 & $5-11$ & Mild & 8 & 5-11 & Mild \\
\hline Control 3 & 0 & $0-4$ & Very Mild & 0 & $0-4$ & Very Mild \\
\hline Control 4 & 7 & $5-11$ & Mild & 7 & 5-11 & Mild \\
\hline Control 5 & 16 & $41-60$ & Moderate & 16 & $41-60$ & Moderate \\
\hline Control 6 & 5 & $0-4$ & Very Mild & 5 & $0-4$ & Very Mild \\
\hline Control 7 & 6 & $5-11$ & Mild & 6 & 5-11 & Mild \\
\hline Control 8 & 10 & $12-23$ & Moderate & 10 & $12-23$ & Mild \\
\hline Control 9 & 5 & $0-4$ & Very Mild & 7 & $5-11$ & Mild \\
\hline Control 10 & 2 & $0-4$ & Very Mild & 2 & $0-4$ & Very Mild \\
\hline
\end{tabular}


controls overlap with four of the incipient stutterers ratings. These scoring inadequacies suggest the SSI is not a reliable measure of stuttering at the low severity levels.

This data suggests the SSI scoring system is not sensitive enough to discriminate between an incipient stutterer and normally disfluent children. The inherent problems with the SSI severity ratings suggests that a clinician look at additional diagnostic information in assessing the disfluencies of children. Further diagnostic indicators aside from SSI scores might by specific disfluency types.

The second question posed in the study was whether or not the disfluency types not addressed in the SSI provided information which would aid in the differential diagnosis. Four of the six disfluency types, polysyllabic word repetitions , intrusive schwas, tense pauses, and revision/incomplete phrases, were found to be statistically significant between the sample populations. The other two excluded disfluency types were not statistically significant.

The data revealed that the incipient stutterers exhibited a high rate of part-word repetitions and monosyllabic word repetitions. These results support the findings of other researchers (Adams, 1977; Riley, 1972; Yairt and Lewis, 1984). This study and others (Haynes and Hood, 1977; Wexler and Mysak, 1982; Yair, 1982) have revealed the monosyllabic word repetitions, along with Interjections and revision/incomplete phrases, are disfluency types most often exhibited by normally disfluent children.

In regards to the question of whether or not the 1972 or 1980 SSI provides a better means of differentially diagnosing the incipient stutterer from the normally disfluent child, the results did not reveal either version to be more reliable. even though monosyllabic word repetitions, a disfluency type considered by some researchers to be characteristic of normally disfluent 
chlldren, is included in the revised SSI. It seemed logical to assume the 1972 SSI would be a better predictor of incipient stuttering. Surprisingly, this study found it did not make a difference as to which SSI verston was used.

The last question to be discussed is whether the two elicitation procedures, picture and open ended questions, for obtaining speech samples exhibited a significant difference between SSI scores. There was not found to be a statistically significant difference between the SSI scores of the different elicitation procedures. Although not statistically significant, the overall total disfluency count was slightly higher for both populations in the picture elicitation procedure with the nonstutterers demonstrating the largest difference. It should be noted that Riley's SSI used a picture elicitation for gathering speech samples of young children. The trend demonstrated in this study suggests that the speech-language pathologist should be aware of the possible effect elicitation style might have on the disfluency output.

The Stuttering Severity Instrument is a simple screening device which has its limitations, but does document more objectively what the child is doing as opposed to straight observation. Clearly, the higher the SSI score the more confidence one can place in it as a diagnostic indicator of inciplent stuttering. 


\section{CHAPTER V \\ SUMMARY AND IMPLICATIONS}

\section{SUMMARY}

Young children between the ages of two and six years often exhibit part-word, whole word, and phrases repetitions as their language develops. This is also the age range when stutterering most frequently appears. Consequently, speech-language pathologists need diagnostic criteria and evaluation tools to distinguish between the incipient stutterer and the normally disfluent child.

Today a widely used evaluation tool is the Stuttering Severity Instrument (SSI) (Riley, 1972, 1980). The SSI is designed to provide a severity level based upon the parameters of frequency, duration, and physical concomitants. Riley (1972) first designed the SSI to not include monosyllabic word repetitions in the frequency count; however, he revised the SSI in 1980 to include monosyllabic word repetitions without providing new normative data nor standardization. It was questionable as to whether the SSI was a sufficiently sensitive means to determine stuttering severity for young children and to whether or not it was strengthened or weakened by the addition of whole monosyllabic words.

The primary question addressed was: Does the SSI discriminate between inciplent stutterers and nonstutterers between the ages of two and six? 
The following secondary questions were also addressed:

1. Do disfluency types not addressed in the SSI contribute information which would provide a stronger discrimination between incipient stutterers and normally disfluent children?

2. Does either the incipient stutterers or nonstutterers exhibit a significant difference between the SSI scores of the speech samples elicited from picture sequence cards and open-ended questions? 3. Does the 1972 or 1980 SSI provide a better means of differentially diagnosing the incipient stutterer from the normally disfluent chlld?

Two groups of subjects were used in this study: one containing ten children, between the ages of two and six identified as stutterers by their primary caretaker and the second containing ten nonstutterers matched for age and sex of the stuttering subjects. All children were selected from the Portland metropolitan area and met the selection criteria. Spontaneous speech sample were obtained and recorded for each subject. The investigator then administered the SSI and categorized nine disfluency types.

The Mann-Whitney $U$ was used to analyze the data for the primary question. A statistically significant difference between the groups of incipient stutterers and nonstutterers SSI scores was found at the .002 level of confidence. The SSI did not discriminate at an individual subject level. Often the SSI scores between the inclplent stutterers and nonstutterers overlapped. In addition, the normally disfluent children were labeled as stutterers varying from very mild, to muld or moderate severities. 
The results for the secondary questions yielded the following conclusions:

1. Four of the six disfluency types observed,polysyllabic word repetition, tense pauses, intrusive schwas and revision/incomplete phrases were found to be statistically significant at the .05 level of confidence.

2. Neither population exhibited a stgnificant difference between the elicitation procedures used to gather a speech sample. Although not significant, a slight increase in the total disfluency count was present in the picture elicitation among both groups.

3. Neither the 1972 nor 1980 versions of the SSI provided a statistically significant difference which would indicate that either version would be a better means of discriminating between the incipient stutterers and normally disfluent children.

The results of this study indicate that the SSI labels normally disfluent children as stutterers as well as resulting in overlapping scores between the two sample populations. These inherent problems suggest that the speechlanguage pathologist should look at additional diagnostic indicators in assessing the disfluencies of children.

\section{CLINICAL IMPLICATIONS}

The results of this study provide useful information for the speechlanguage pathologist who is faced with making a differential diagnosis between the incipient stutterer and the normally disfluent child. This study 
found that the SSI labels normally disfluent children as very mild, mild or moderate stutterers. In addition, the SSI results in overlapping scores of a normally disfluent child and incipient stutterer. Consequently, it is difficult to make a confident diagnosis regarding young children's fluency without further observation of the child's speech characteristics, specifically the frequency and occurrence of all disfluency types. As found in other fluency research, this study also suggests an emphasis be placed on dysrhythmic phonations and part-word repetitions as indicators of a possible fluency problem. This study also found monosyllabic word repetitions to be a frequent disfluency type of normally disfluent children as well as incipient stutterers. Monosyllabic word repetitions are included in the administration of the 1980 SSI but were not part of the 1972 SSI. Speech-language pathologists need to consider this data when using the SSI, as this instrument Includes the monosyllabic word repetition disfluency type in the determination of stuttering severity. These findings suggest the speechlanguage pathologist should use the SSI with some reservations, especially with young children who obtain mild and moderate rankings. It should not be the sole source of information from which to make a differential diagnosis.

The data gathered on the possible effects of elicitation procedures should also be considered when obtaining speech samples for assessing fluency problems. 


\section{RESEARCH IMPLICATIONS}

The results of this study indicate a need for collecting normative data for preschool children on the SSI in order to delineate the scores and characteristics between the incipient stutterer and normally disfluent children. The need for further research on differential diagnostic methods is tantamount to providing appropriate intervention.

Examining the different types of disfluency exhibited by inciplent stutterers and normally disfuent children would contribute to a better means of differentially diagnosing and possibly aid in the development of appropriate fluency assessment tools.

Because the sample size was small, it is difficult to generalize to either the stuttering or normally disfluent population. Therefore, research involving a larger sample stze of young children is needed to provide additional Information of SSI scores and the frequency and occurrence of specific disfluencies so a more confident diagnosis can be made regarding disfluent speech.

It would be interesting to determine if elicitation procedures, influences from environment, listener and/or situational stress, have an influence on the fluency of young children and inciplent stutterers. 


\section{REFERENCES}

Adams, M. (1977). A clinical strategy for differentiating the normally nonfluent child and the incipient stutterer. Journal of Fluency Disorders, 2, 141-148.

Adams, M. (1980). The young stutterer: Diagnosis, treatment and assessment of progress. Seminars in Speech, Language and Hearing, 1, 289-198.

Andrews et al., (1983). Stuttering: A review of research findings and theories circa 1982. Journal of Speech and Hearing Disorders, 48, 226-246.

Christianson, P. (1987). Disfluencies in Normal Three-Year Old and Flve-Year Old Male Children. Masters Thesis. Portland State University.

DeJoy, D. and Gregory, H. (1985). The relationshtp between age and frequency of disfluency in preschool children. Journal of Fluency Disorders, 107-122.

Dunn, L.M. (1981). Peabody Picture Vocabulary Test-Revised. Circle Pines. Minnestota: American Guidance Service.

Haynes, W.O. and Hood, S.B. (1977). Language and disfluency variables in normal speaking children from discrete chronological age groups. Journal of Fluency Disorders, 2, 57-74.

Johnson, W. (1959). The onset of stuttering. Minneapolis University of Minnesota Press.

Johnson, W., Darley, F., and Spriestersbach, D. (1963). Diagnostic methods in speech pathology. New York: Harper \& Row.

Panelli,C., McFarlene, S.C., and Shipley, K. (1978). Implications of evaluating and intervening with incipient stutterers. Journal of Fluency Disorders, 3, 41-50.

Pindzola, R. and White, D. (1986). A protocal for differentiating the incipient stutterer, Language Speech and Hearing Services in Schools, 1, 2-11.

Meyers, S. (1989). Nonfluencies of preschool stutterers and conversational partners: observing reciprocal relationships. Journal of Speech and Hearing Disorders, 54, 106-112.

Riley, G. (1972). A stuttering severity instrument for children and adults. Journal of Speech and Hearing Disorders, 37, 314-320. 
Riley, G. (1980). Stuttering Severity Instrument for Children and Adults.

Thgard, Oregon: C.C. Publications, Inc.

Riley, G. (1988). Letter to the editor. Journal of Fluency Disorders, 13, 153155.

Semler, C. (1987). The differential Role of the SSI with Normal Preschool Children. Masters Thesis. Portland State University.

Slegel, S. (1956). Nonparametric statistics for behavioral sciences.

New York: McGraw-Hill Book Co.

Silverman, E. (1972). Generality of disfluency data collected from preschoolers. Journal of Speech and Hearing Research, 15, 84-92.

Starkweather, C.W. (1985). The development of fluency in normal children. In Stuttering Therapv: Prevention and Intervention with Children. Memphis, Tennessee: Speech Foundation of America.

Wexler, D. (1982). Developmental disfluency in 2, 4, 6 year old boys in neutral and stress situations. Journal of Speech and Hearing Research, $25,229-234$.

Wexler, K.B. and Mysak, E.D. (1982). Disfluency characteristics of 2-, 4-, and 6-year old males. Journal of Fluency Disorders, 7, 37-46.

Williams, D., Silverman, F. and Kools, J. (1968). Disfluency behavior of elementary school stutterers and nonstutterers: The adaptation effect. Journal of Speech and Hearing Research, 11, 622-630.

Yairi, E.. (1981). Disfluencies of normally speaking two-year old children. Journal of Speech and Hearing Research, 24, 490-495.

Yatrl, E. and Lewis, B. (1984). Disfluencies at the onset of stuttering. Journal of Speech and Hearng Research, 27, 154-159. 
APPENDIX A

LETTER TO PARENTS AND PERMISSION TO

PARTICIPATE IN STUDY FORM 
APPENDIX A

Dear

I am a graduate student at Portland State Untversity conducting a study on identifying repetitions in the speech of preschool children. I am determining the value of an evaluation procedure of Identifying children who stutter. Many children demonstrate stuttering behavior during their preschool years. However, it has been shown that most preschool children "outgrow" this type of speech behavior. I am interested in obtaining information on the speech of preschool children. In order to conduct this study, I need children who appear to stutter and children who do not.

This study can be accomplished by a 15 minute videotaped interview with your child talking with me. The videotaping will be done at Portland State University at a time convenient for you and the department. Your child's name will not be used in reporting the results and the videotapes will only be avallable to authorized university personnel. Your child may be excused from participation in this study at any time without penalty.

Prior to the videotaped session, your child will be given a brief test of word meanings called the Peabody Picture Vocabulary Test-Revised. you will also be asked to complete a brief questionnalre about your child's speech and language development. Children will be selected to participate in this study based on the responses to the questionnalre; therefore, not all children will be selected to participate. If you have any questions as a result of your participation of this study, please contact Robert TInnin, Office of Graduate Studies and Research, 105 Neuberger Hall, Portland State University, 229-3423.

Please complete the information on the attached sheet, indicating your apporval and willingness to participate in this study, and return this form to me immediately in the envelope provided.

It is important that I schedule the taping sessions as soon as possible. Please call me at 656-2810 if you have any questions. I appreciate your cooperation.

Sincerely,

Brenda Pekkola 
APPENDIX B

PARENT PERMISSION FORM 


\section{APPENDLX B}

Child's Name:

Birthdate:

Age:

Parent's Name

Address:

Telephone:

1. Is English the primary language spoken in your home? yes no

2. Has your child had an ear infection within the last 6 months? yes no

3. Has your child ever been diagnosed with any of the following? developmental delay: mental retardation: yes neurological impairment: yes orthopedic or physical handicap allergies hearing loss

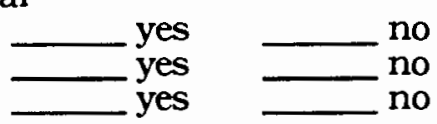
no

4. Have you ever been concerned about your child's fluency or sought counseling for fluency concerns? yes no

5. Has your child ever received speech therapy for stuttering? yes no

I hereby give permission for my child, , to participate in this study. My child may attend a videotaping session and participate in a brief test of receptive vocabulary. I will complete the questionnaire and I understand I can withdraw my permission at any time during this study. 
APPENDLX C

QUESTIONNAIRRE 


\section{APPENDIX C}

Child's Name: Birthdate

Address: Telephone:

Relationship of person completing this questionnaire:

What language is spoken mostly in your home?

Does your child speak another language? yes If so what language?

What is your child's ethnic background?

I. List the children and adults living in your home. NAMES AGE RELATIONSHIP TO CHILD

II. Does your child stutter? yes no (If no go to section III) When did you first notice that your child stutters?

\begin{tabular}{llll}
\hline Has anyone else commented on this? & yes__ no_ If so,
\end{tabular} who?

Have you consulted other professionals about your child's stuttering? yes no. If so, what were their recommendations?

What things have you tried, if any, to change your chlld's speech?

Does your child's speech change when she talks with: (Answer yes or no) A friend A younger sibling

A familiar adult other than a parent

A teacher( or authority figure) A parent

Describe other times when you notice changes in your child's speech,

When ts your child's speech best?

When is your child's speech worst?

When your child stutters, what do you do?

Describe what your child does when he/she stutterers.

Does it bother your child?___ yes __ no

Does it bother anyone else?__yes n__ no

Does your child ever do any on the following when stuttering?

a. stretch sounds out? (ex.mmmmmy ball)

b. "get stuck" in the middle of words? (ex. b: aseball) no 

c. repeat words (ex. I-I-I- want the ball)
d. repeat sounds (ex. I want the ball)
e. repeat phrases (ex. I want-I want the ball)
f. change a sentence (ex. I seen-I saw a cat)

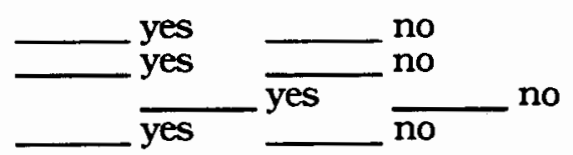
Does your child repeat: often some never

Does your child repeat easily or with effort?

III. Does your child do any of the following when speaking? (Answer yes or no)

$\begin{array}{lll}\text { Make faces } & \text { Move the head___ } & \text { Move arms } / \text { legs } \\ \text { Nolsy breathing } & \text { Tongue clicking } \\ \text { Other } & \end{array}$

When did your child say her first word?

What was your child's first word?

When did your child first walk?

When was your child tollet trained?

Describe how your child learned to talk compared to other children in your family.

early late slow easy hard

Has your child ever attended school? yes If so, where? no

How long has your child attended school?

IV. Does any other member of your family stutter now or have they ever stuttered? yes no

If so, who? Name (Optional) Relationship to chlld

What was the last grade completed in school by the primary caretaker of this child?

Occupation of caretaker? 
APPENDLX D

LIST OF STIMULI 
APPENDIX D

\section{TOYS}

1 telephone

2 cars

2 medium-sized rubber toys (Gumby and Pokey)

2 puppets

1 wind-up toy

2 dolls

Tea and plate set

Fischer Price Farm Set with extra animals

\section{QUESTIONS}

Where is your Dad/Mom/sister/brother/dog today?

What are they doing?

What toys do you have at your house?

Have you ever been to a real farm?

What did you see there?

What do you do at school?

What are you going to do when you go home?

\section{PROMPTS}

You did?

Tell me about it.

Why?

MMM HMMM.

$\mathrm{Oh}$.

Pretending to talk on the telephone

Pretending to drink tea

Modeling puppetry

I wonder if.... 
APPENDIX E

CODING SYMBOLS 


\section{APPENDIX E}

Part word repetition

Phrase repetition

Dysrhythmic phonation

Revision/incomplete phrases

Interjection

Monosyllabic whole word repetition

Polysyllabic whole word repetition

Intrusive schwa

Tense pause
PW

PHR

DP

RIP

I

MSWR

PSWR

IS

TP 


\section{APPENDIX F}

THE SSI'S MANUAL ADMINISTRATION INSTRUCTIONS (RILEY, 1980) 


\section{APPENDIX F}

\section{Administering the SSI to Nonreaders}

Children below a third grade reading abllity are included in the nonreader group. A cartoon sequence, which has the captions removed, is used to elicit a speech sample. The child is asked to "Tell the story that goes with these pictures.". The speech sample should be tape-recorded. The examiner should make a dot for each word spoken fluently and a slash for each word stuttered. Reliability can be tested by repeated listening to the recorded tape. Any silent or audible prolongation and any sound or syllable repetition are considered a stuttering block. Phrase repetitions, rephrasing, and whole word repetitions of more than one syllable are not counted as stuttered blocks. A total sample of at least 150 words is required for scoring the SSI.

To arrive at a frequency count, omit the first and last 25 words and then count the number of stuttered words in the 100 word sample. Bracket the 100 words used. This count is the number of blocks in 100 words (a percentage). The table on the test form can be used to convert this percentage into a task score. If fewer than 100 words have been spoken, the percentage must be computed. In either case, do not include the first 25 words in the frequency count. The result of the count converted to a task score will yield a numerical value between zero and 18 . Record this number in the box to the right of the page marked "Total Frequency Score".

The duration average of the three longest blocks and observations of physical concomitants are based on the entire speech sample. The duration score is converted to points on the following scale:

$\begin{array}{ll}\text { Fleeting } & 1 \text { point } \\ \text { One-haif second } & 2 \text { points } \\ \text { One full second } & 3 \text { points } \\ 2-9 \text { seconds } & 4 \text { points } \\ 10-30 \text { seconds } & 5 \text { points } \\ 30-60 \text { seconds } & 6 \text { points } \\ 60 \text { seconds }+ & 7 \text { points }\end{array}$

The task score for "Duration" should be recorded in the box marked "Total Duration Score". 
Table 1. Percentile and severity equivalents of SSI raw scores $(\mathrm{N}=109)$.

\begin{tabular}{ccc}
\hline & & \\
Total & Percentle & Severity \\
\hline $0-5$ & $0-4$ & Very Mild \\
\hline & & \\
$6-8$ & $5-11$ & Mild \\
$14-15$ & $12-23$ & \\
\hline $16-19$ & $24-40$ & Moderate \\
$20-23$ & $41-60$ & \\
$24-27$ & $61-77$ & Severe \\
\hline $28-30$ & $78-89$ & \\
$31-45$ & $90-96$ & Very Severe \\
\hline
\end{tabular}


APPENDIX G

SSI SCORING PROCEDURES FOR RELIABLITY JUDGES 


\section{APPENDIX G}

PART ONE: General Instructions

You will be presented with six videotaped segments randomly selected by an individual not involved in the study, 3 from the group identified as incipient stutterers and 3 from the normally disfluent group. The videotaped segments each contain 150 word speech samples.

The purpose of this reliability is to determine the investigators accuracy at administering the SSI for nonreaders specifically, the identification of part-word repetitions, monosyllabic whole word repetitions, prolongations, dysrhythmic phonations, duration of blocks and physical concomitants. The following are operational definitions of these terms:

1. Part word repetition: The repetition of a sound or syllable unit which is less than the entire word. For example, s-s-say or ma-ma-maybe.

2. Monosyllabic whole word repetition: The repetition of an entire single syllable word. For example, car-car.

3. Prolongation: The lengthening in time of a speech sound or articulatory posture of the speech mechanism.

4. Dysrhythmic phonations: The audible or silent continuation of a sound or articulatory posture which disturbs or distorts the normal rhythm or flow of speech (Williams, Silverman, \& Kool, 1968). Dysrhythmic phonations occur within words and include broken words.

5. Duration of blocks: The estimated length of each block.

6. Physical concomitants: The visual and audible phenomena which accompany the stuttered speech (Riley, 1972). Riley (1972) lists four categories of physical concomitants : distracting sounds (e.g., hissing noise, throat clearing), distracting facial grimaces (e.g., eye blinks, tongue protrusion), distracting head movement (e.g., turning head from listener, looking at floor), and distracting movements of the extremities (e.g., foot tapping, arm swaying). 
PART TWO: Procedures for Identification and Scoring

A technician will play the videotaped segments, playing the entire 150 word speech sample at once while the raters identify the disfluencies.

The following rules should be used when evaluating disfluencies using the SSI:

1. The first and last 25 words are omitted for the frequency count.

2. Raters are only responsible for identification of part-word repetitions, monosyllabic whole word repetitions, dysrhythmic phonations, and prolongations for the frequency count.

3. No matter how many times a monosyllabic word repetition or part-word repetition is is repeated it is only credited as one disfluency.

4. The entire 150 word speech sample is used to evaluate the duration and physical concomitant score.

5. Identify disfluencies by marking a / symbol and fluent words by marking a symbol. For example, The b-boy and girl are s-s-sleepy would be coded as $\cdot 1 \cdot \cdots /$.

6. When whole phrases are repeated, the words are counted only as once. For example. "He went home-he went home yesterday" would be counted as 3 fluent words instead of six.

7. Raters are responsible for tabulating the raw scores for frequency, duration, and physical concomitants and then assigning a task score based upon the corresponding chart for each of the 3 sections.

8. Raters are responsible for calculating the total overall raw score and assigning a percentile and severity level by using the Severity Conversion chart for nonreaders.

PART THREE: Reliability Training

A training session will be conducted prior to the actual reliability testing, by the investigator, using the same procedures as outlined above. The training session will include practice in administering the SSI for three different speech samples. The reliability raters must be in 100 percent agreement for the percentile and severity levels assigned before reliability testing will begin. Any differences will be discussed with all members of the reliability team until everyone is in agreement. 
APPENDIX H

STUTTERING SEVERITY INSTRUMENT TEST FORM 


\section{Stuttering Severity Instrument} TEST FONM

NAME

SCHOOL

EXAMINEA

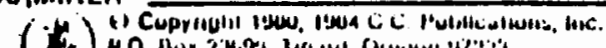

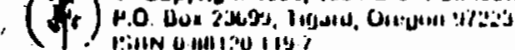

by Clyndon D. Riloy, Ph.D.

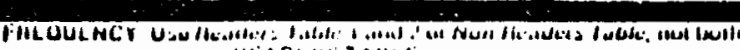

\begin{tabular}{|c|c|c|c|}
\hline \multicolumn{2}{|c|}{ 1. Jub Tosh } & \multicolumn{2}{|c|}{ 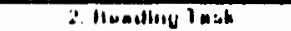 } \\
\hline 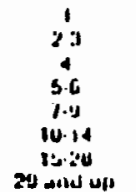 & $\begin{array}{l}\vdots \\
1 \\
1 \\
\vdots \\
1 \\
11 \\
1\end{array}$ & 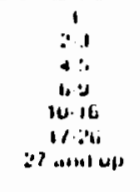 & $\begin{array}{l}: \\
\vdots \\
1 \\
1 \\
1\end{array}$ \\
\hline
\end{tabular}

irx M F

GRADE

ONIE: OIF BIIITTH

Datr

AGE

IHE.ADIII NON.AEADEA

DUintion

\begin{tabular}{|c|c|}
\hline Eollenated tenoth of Tinue kanuest llluchs & Sccure \\
\hline 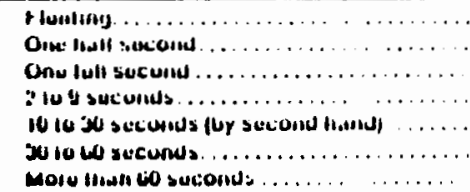 & 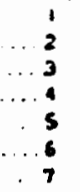 \\
\hline
\end{tabular}

\begin{tabular}{|c|c|c|}
\hline \multicolumn{2}{|c|}{ 7. Phlutulask } & \\
\hline 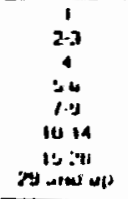 & $\begin{array}{l}+ \\
4 \\
11 \\
11 \\
1 . \\
14 \\
16 \\
10\end{array}$ & $\begin{array}{l}\text { Froauchey } \\
\text { Joeh score } \\
\text { l end } z \\
\text { or } 3\end{array}$ \\
\hline
\end{tabular}

PHTSICAL CONCOMITANTS

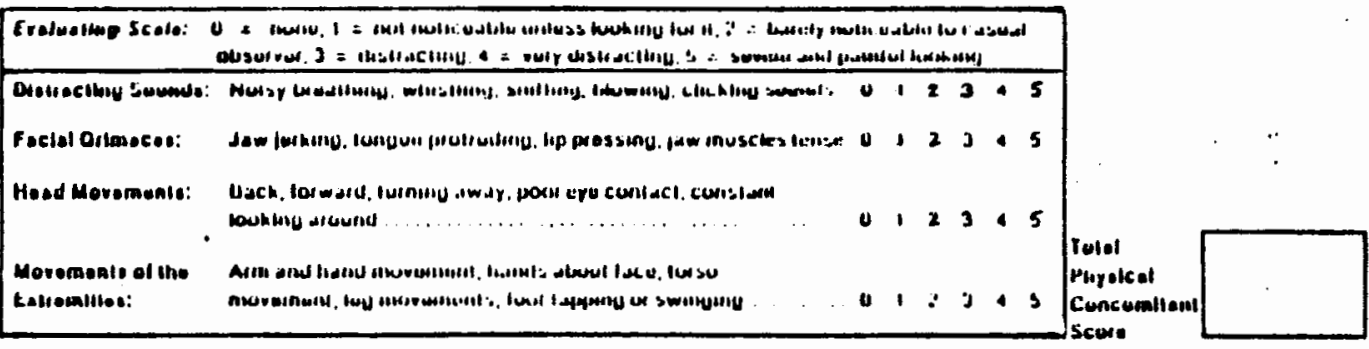

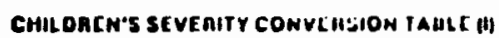

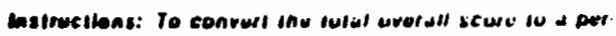

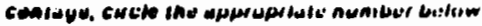

\begin{tabular}{|c|c|c|}
\hline 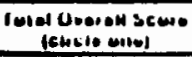 & Percenille & Soroolly \\
\hline $0:$ & u. & 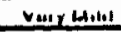 \\
\hline $\begin{array}{l}60 \\
9.13 \\
14.15\end{array}$ & $\begin{array}{c}311 \\
12.21 \\
24.10\end{array}$ & Malla \\
\hline $\begin{array}{l}16.15 \\
2023 \\
\end{array}$ & $\begin{array}{l}41.64 \\
61.11 \\
\end{array}$ & Movdur als \\
\hline $\begin{array}{l}24 \cdot 27 \\
7434 \\
\end{array}$ & 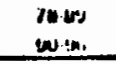 & Sorvere \\
\hline $34 \cdot 43$ & $y / \cdot 100$ & Very surene \\
\hline
\end{tabular}

Tolol

Oreiall Scere

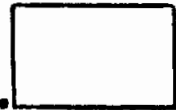

AUULI: SL VEATY CONVEHSHON TAULE AH

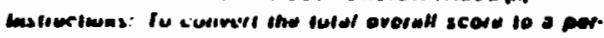

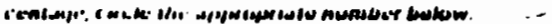

\begin{tabular}{|c|c|c|}
\hline 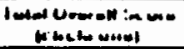 & Peocentile & soverlur \\
\hline 416 & 04 & Vory muls \\
\hline $\begin{array}{l}110 \\
421\end{array}$ & $\begin{array}{l}511 \\
1773\end{array}$ & moro \\
\hline 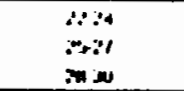 & $\begin{array}{l}74.40 \\
41.61 \\
1.11\end{array}$ & Modelaie \\
\hline $\begin{array}{l}313.1 \\
\text { in } 1.0 .\end{array}$ & 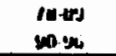 & Sovere \\
\hline 34 & $\$ 1 \cdot 00$ & very Sorere \\
\hline
\end{tabular}


APPENDIX I

INSTRUCTIONS TO RELLABILITY JUDGES 


\section{APPENDIX I}

PART ONE: Instruction for Selecting of Content Transcripts for Reliability Testing

Read the attached instructions to the individual responsible for preparation of content transcription for reliability testing.

\section{PART TWO: General Instructions}

You will be given six partially complete transcripts randomly selected from a group of 2 to 6 year old children. These transcripts contain 10 utterances and are only partially complete. The transcripts contain only the content of the utterances The transcripts do not include any type of disfluency such as: phrase repetitions, revision/incomplete phrases, interjections, part-word repetitions, whole-word repetitions, dysrhythmic phonations and tense pauses. Remember that these transcripts may not be perfect and that mistakes can be made even in determining the content of the episodes. Listen to the entire episode and see if you agree with all the words that have been given to you, then add the additional words you are hearing along with all disfluencies.

The purpose of this reliability testing is to determine the investigator's accuracy at identifying monosyllabic whole-word repetitions, polysyllabic whole-word repetitions, part-word repetitions, dysrhythmic phonations, revision/incomplete phrases, interjections, phrase repetitions, intrusive schwas, prolongations, and tense pauses. The following are definitions of these terms:

1. Monosyllabic whole word repetitions: The repetition of an entire word single syllable word. For example, car-car.

2. Polysyllabic word repetition: The repetition of an entire word which is comprised of two or more syllables. For example, because-because. 
3. Part-word repetition: The repetition of a sound or syllable unit which is less than the entire word. For example, s-s--say or ma-ma-maybe.

4. Dysrhythmic phonations: The audible or silent continuation of a sound or articulatory posture which disturbs or distorts the normal rhythm or flow of speech (Willams, Silverman, \& Kool, 1968). Dysrhythmic phonations occur within words and include broken words.

5. Revision/incomplete phrase: Making a new version of a phrase to alter a thought, word, or Idea. For example, he was g-he was going.

6. Interjections: A sound inserted within the flow of speech which is not part of the message. For example, uh, er, um, well.

7. Phrase repetitions: The unintentional repetition of two or more words.

8. Intrustve schwa: A substitution of the schwa for a vowel which often occurs in the syllable being repeated (Adams, 1977). For example, puh-puh-paper or buh-buh-buh-baby.

9. Prolongation: The lengthening in time of a speech sound or articulatory posture of the speech mechanism.

10. Tense pause: A disfluency that occurs between words, part words and nonwords. When at the between point in question there are barely audible manifestations of heavy breathing or muscular tightening. The same phenomena within a word would place the word in the category of dysrhythmic phonation (Williams, Silverman, \& Kool, 1968).

PART THREE: $\quad$ Procedures for Transcription and Identufication of Disfluencies

An Individual not involved in this study has prepared content transcripts (Appendix J). Reliability raters will be given these transcripts. A technician will then play the corresponding segment of the videotape that matches the content transcripts. Initially, all ten utterances were shown in their entirety to the reliability raters. The technician will then play the video segment again only showing the raters one utterance at a time. The raters will be responsible for filling in all missing parts of the transcripts, Including words that have been deleted and all disfluencies. It should be noted that the raters are responsible for making any changes in transcripts due to errors made by the individual selecting content transcripts. 
The following rules should be used when transcribing and identifying

disfluencies:

1. Raters are responsible for identification of phrase repetitions,part-word repetitions, dysrhythmic phonations, revision/incomplete phrases, interjections, monosyllabic whole word repetitions, intrusive schwas, prolongations, and tense pauses.

2. Use the following key to identify disfluencies:

$\begin{array}{ll}\text { PW: } & \text { Part word repetition } \\ \text { PHR: } & \text { Phrase repetition } \\ \text { DP: } & \text { Dysrhythmic phonation } \\ \text { RIP: } & \text { Revision/Incomplete phrase } \\ \text { I: } & \text { Interjection } \\ \text { MSWR: } & \text { Monosyllabic whole word repetition } \\ \text { PSWR: } & \text { Polysyllabic whole word repetition } \\ \text { IS: } & \text { Intrusive schwa } \\ \text { PROL: } & \text { Prolongation } \\ \text { TP: } & \text { Tense pause }\end{array}$

3. No matter how many units of part word, word, or phrase repetitions occur, only one was credited as an instance of disfluency.

4. An utterance may have a combination of any of the disfluency types and should be credited as separate disfluencies if this occurs. For example. f-fire-fire should be scores as 1 part word repetition and 1 monosyllabic whole word repetition. Th-the-the sun-the moon would be scored as 1 partword repetition, 1 monosyllabic whole word repetition, and 1 revision/incomplete phrase.

5. Repetitions for the first part of a contraction such as it-it's and I-I'm should be credited as a part word repetition since the contraction functions as a single word for the young child and was calculated as one word when determining the word count for the initial transcripts.

\section{PART FOUR: Reliability Training}

A training session will be conducted prior to the actual reliability testing, by the Investigator, using the same procedures as outlined above. The training session will include the practice of disfluency identification.

The reliability raters must be in 100 percent agreement with each other to start reliability testing. Any differences will be discussed with all members of the reliablity team until everyone is in agreement over the disfluency identification. 
APPENDIX J

INSTRUCTIONS FOR SELECTION OF CONTENT TRANSCRIPTS FOR RELIABILITY TESTING 


\section{APPENDIX J}

Videotapes have been made of a child and an adult interacting in a parallel play situation. The children's conversations in these videotapes have been transcribed verbatim, and these transcripts are what you will be workdng from. You are responsible for extracting ten episodes from each of the six transcripts you are given and forming a content transcript for each one. A content transcript can be defined as the basic information of an utterance provided by the chlld. deleting any type of discontinuity, such as; interjections (I) , part-word repetitions (PW), monosyllabic word repetitions (MSWR), polysyllabic whole word repetitions (PSWR) , phrase repetitions (PHR), dysrhythmic phonations (DP), and revision/incomplete phrases (RIP). There are spectfic guidelines that you need to follow when developing these content transcripts.

\section{A) Guidelines}

1. Use episodes 26-35 from each of the six transcripts to form content episodes.

2. Additional words should not be added to the episodes, only use those words that are present in the transcripts.

3. It may be necessary with some episodes to include the full episode that was presented on the transcript, this is especially true if the episodes are very short and do not include any discontinuities. 
For example the following episodes would be included in the content transcripts in full:
a. hi
b. and those
c. her name is Sally

4. Discontinuities in the basic transcript should not be included in the content transcript, this includes: phrase repetitions, part word repetitions, monosyllabic and polysyllabic word repetitions, prolongations, interjections, and revision/incomplete phrases. For example, "I-I-I am going." would be written, "I am going." and "uh I need uh I need to talk" would be written "I need to talk."

5. In transcribing revision/incomplete phrases into content episodes only include the most complete form of the episode. For example, "It is a ze-it is a giraffe" would be written. "It is a giraffe." and "Please set the chair-table." would be written, "Please set the table."

6. An unintelligible episode would be labeled as an unintelligible episode. If only part of the episode is unintelligible and the rest has been transcribed, label the unintelligible segment and include the transcribed section in its most complete form.

7. Any additional sounds or pulses at the beginning, middle or end of the episode should not be included in the content transcript. 
8. Examples of Full Transcription and Corresponding Content Transcription

Full Transcription

1. I don't know

2. I he I already tell him

3. Unintelligible episode

4. yah

5. you have a tea part with us?

6. w-w-wh-where is she?

7. I think sh-she got to sit

8. and when she wakes

(rest of utterance

unintelligible)

\section{Content Transcription}

1. I don't know.

2. I already tell him

3. Unintelligible episode

4. yah

5. you have a tea party with us?

6. where is she?

7. I think she got to sit

8. and when she wakes (rest of utterance unintelligible) 